NBER WORKING PAPER SERIES

\title{
ESTIMATING BANK TRADING RISK: \\ A FACTOR MODEL APPROACH
}

\author{
James O'Brien \\ Jeremy Berkowitz \\ Working Paper 11608 \\ http://www.nber.org/papers/w11608
}

\author{
NATIONAL BUREAU OF ECONOMIC RESEARCH \\ 1050 Massachusetts Avenue \\ Cambridge, MA 02138 \\ September 2005
}

Prepared for the NBER Conference on the Risks of Financial Institutions. We are grateful for the substantial help of Mathew Chesnes in developing programs and compiling data bases and to Anthony Cho for valuable research assistance. For helpful suggestions, we would like to thank Andy Lo, Sean Campbell, Paul Kupiec (our discussant), Ken Abbott (our discussant), Peter Christoffersen, Mark Flannery, Bill English, Egon Zakrajsek, Alexandre Baptista, Andrew Karolyi and the editors, Mark Carey and Rene Stulz. The views expressed are solely those of the authors. The views expressed herein are those of the author(s) and do not necessarily reflect the views of the National Bureau of Economic Research.

(O2005 by James O'Brien and Jeremy Berkowitz. All rights reserved. Short sections of text, not to exceed two paragraphs, may be quoted without explicit permission provided that full credit, including $\odot$ notice, is given to the source. 
Estimating Bank Trading Risk: A Factor Model Approach

James O'Brien and Jeremy Berkowitz

NBER Working Paper No. 11608

September 2005

JEL No. G21

\begin{abstract}
$\underline{\text { ABSTRACT }}$
Risk in bank trading portfolios and its management are potentially important to the banks' soundness and to the functioning of securities and derivatives markets. In this paper, proprietary daily trading revenues of 6 large dealer banks are used to study the bank dealers' market risks using a market factor model approach. Dealers' exposures to exchange rate, interest rate, equity, and credit market factors are estimated. A factor model framework for variable exposures is presented and two modeling approaches are used: a random coefficient model and rolling factor regressions. The results indicate small average market exposures with significant but relatively moderate variation in exposures over time. Except for interest rates, there is heterogeneity in market exposures across the dealers. For interest rates, the dealers have small average long exposures and exposures vary inversely with the level of rates. Implications for aggregate bank dealer risk and market stability issues are discussed.
\end{abstract}

\author{
James O'Brien \\ Division of Research and Statistics \\ Board of Governors of the Federal Reserve \\ System \\ Washington, DC 20551 \\ jmobrien@frb.org \\ Jeremy Berkowitz \\ Department of Finance \\ University of Houston \\ 334 Melcher Hall \\ Houston, TX 77204-6021 \\ jberkowitz@uh.edu
}




\section{Estimating Bank Trading Risk: A Factor Model Approach}

\section{Introduction}

Bank dealers play a central role in securities and derivatives markets and are active traders in their own right. Their trading risks and risk management are important to the banks' soundness and the functioning of securities and derivatives markets. In this paper, we use proprietary daily trading revenues of 6 large bank dealers to study their market risks using a market factor model approach. We estimate the bank dealers' exposures to exchange rate, interest rate, equity, and credit market factors.

Traditionally, the safety and soundness of the banking system has been the principal focus of interest in bank dealer risk. Important for this purpose is the level of market risk taken by bank dealers and commonality in their risk exposures. In recent literature, the focus has been extended to the effects of bank dealer and other trading institutions’ risk management policies on market stability. In using risk measures based on market volatility and in particular Value-at-Risk (VaR), it has been argued that institutions’ demands for risky assets will move together, which will lead to exaggerated price movements and market instability. When market volatility is low, institutions will increase demands to hold risky assets, putting upward pressure on prices and, when market volatility becomes high, institutions will attempt to reduce their positions in risky assets, putting downward pressure on prices. This behavior is said to have exaggerated market instability in the late summer and fall of 1998 following the Russian ruble devaluation and debt moratorium and the near failure of LTCM. ${ }^{1}$

\footnotetext{
${ }^{1}$ For dynamic analyses of market effects of a VaR constraint, see Basak and Shapiro (2001), Danielsson, Shin, and Zigrand (2002), Persaud (2002), and Morris and Shin (1999). For different analyses of the risk-taking incentives and portfolio choice effects of a VaR constraint, see Basak and Shapiro (2001), Cuoco and Liu (2003), and Alexander and Baptista (2004).
} 
Despite the strong interest, there has been little study of bank dealer risks and risk management and there appears to be little formal evidence on the size, variation, or commonality in dealer risks. In significant measure, this owes to limited public information on dealer positions and income which limits the study of dealer risks and risk management. Individual banks report on trading positions and revenues only quarterly and reporting is limited to securities and derivatives in broad market categories. While there is weekly reporting, it includes security positions and transactions but only limited information on derivatives and data is reported only for aggregated primary (bank and non-bank) dealers. ${ }^{2}$

Bank VaRs, which forecast the maximum loss on the trading portfolio with a given confidence, provide a direct measure of market risk. However VaRs do not reveal the dealers’ underlying market exposures or their size. Berkowitz and O’Brien (2002) also found the risk forecast performance of the daily VaRs for the banks examined in this study to be weak. Further, there was no common pattern in the correlation of VaRs across the banks.

Here we apply a factor model to the daily trading revenues of 6 large bank dealers to estimate their market risk exposures. Factor models have long been used to study portfolio and firm market risks (e.g., Chen, Roll and Ross (1986), Flannery and James (1984)). Closer to our objectives is their application to mutual fund and hedge fund returns to characterize the market risks in the funds’ portfolios (e.g., Sharpe (1992), Fung and Hsieh (1997)).

With daily trading revenues, we can study the effects of daily market price moves on the banks' trading portfolios. Also, the sample sizes are large, about 1200 daily observations per bank. However, the trading revenue data is subject to significant limitations as well.

\footnotetext{
${ }^{2}$ Jorion (2005) analyzes bank dealer trading risks and VaRs and implications for systemic market risk using quarterly reported trading revenues and VaR-based market risk capital requirements. Adrian and Fleming (2005) provide a description of data collected and reported for primary securities dealers and present some evidence on dealer risk-taking based on dealer financing data.
} 
Risk exposures can be inferred only through effects on trading revenues. Trading revenues include fee and spread income and net interest income, as well as market gains and losses on positions. Further, while used by the banks internally and required for VaR model testing, the daily trading revenues lack the accounting scrutiny accorded to quarterly reports.

In the standard factor model, factor coefficients represent estimates of fixed portfolio exposures. For bank dealers, exposures are variable, as dealers actively trade their positions and are not buy and hold investors. Thus, the standard factor model approach may not apply here. This leads us to first consider a factor model framework and estimation issues when positions are variable. The framework is used in implementing two empirical modeling approaches where trading positions are variable.

One approach is a random coefficient model, where the factor coefficients represent randomly varying market factor exposures. Using the random coefficient framework of Hildreth and Houck (1968), the dealers' mean exposures to different market factors and the variances of exposures are estimated. Estimates of average daily market risk exposures are small relative to average trading revenues and cannot account for much of the trading revenue variation. The signs of the exposures also differ across the banks, indicating heterogeneity in average exposures. A notable exception is for the interest rate factor where all banks but one exhibit small net long exposures to interest rate risk.

Even with small average exposures risk-taking could still be large, since dealers could vary positions between large long exposures and large short exposures. Our estimates indicate significant variation in market exposures that include both long and short positions. Nonetheless, the ranges of potential variation in trading revenues due to variation market exposures do not appear large relative to the total variation in trading revenues. 
The random coefficient model is based on highly simplifying assumptions about the variability in exposures. Especially important is the assumption that exposures are independent of the market factors, which conflicts with portfolio strategies that are related to market prices. This issue has also been important in hedge fund studies, some of whom have tailored the functional form of the factor model to certain types of portfolio strategies. It is argued below that specifying an appropriate functional form requires a good deal of specificity on the portfolio strategy. However, our information on bank dealer strategies is too sparse to formulate a specific portfolio strategy or unambiguously interpret results from alternative functional forms that might be used.

A more limited approach to considering market price-dependent trading strategies is taken here. For each bank, a linear factor model with a 150-day rolling sample is estimated. Using historical plots, the 6 banks’ rolling regression factor coefficients are compared to the respective factors' contemporaneous 150-day rolling means. The latter will reflect periods of rising and declining market prices. Of interest is whether the rolling coefficients move systematically with the factors. This would indicate that the dealers’ market exposures vary with the market factors and, hence, a possible price-dependent trading strategy.

For all factors but interest rates, the 6 banks’ rolling factor coefficients show no common movement with the factors' rolling means. For the interest rate factor, the banks' rolling factor coefficients tend to vary inversely with the level of the interest rate. This would be consistent with the interest rate durations for their trading portfolios becoming larger (smaller) when rates are declining (rising).

The samples for the factor regressions include many days when factor changes are small. However, the conclusions are basically the same if we restrict the analysis to days of 
large price movements. The banks' trading revenues do not show a common systematic relation with large price changes for the non-interest rate factors but trading revenues tend to be abnormally low on days of relatively large interest rate increases.

In sum, our principal findings are significant heterogeneity across dealers in their market exposures, relatively small exposures on average and a limited range of long or short exposures. Commonality in dealer exposures is limited to interest rate risk with exposure levels inversely related to the level of rates. The implications of these results for aggregate bank dealer risk and market stability are discussed in the concluding section to the paper.

The remaining sections are as follows. In the next section, the bank data and the distribution of trading revenues are described. The factor model framework and empirical model specifications are developed in section 3. The estimation and results for the random coefficient model are presented in section 4; the rolling regressions in section 5; and the relation between trading revenues and large market price changes in section 6 .

\section{Bank Trading Revenues}

The Basel Market Risk Amendment (MRA) sets capital requirements for the market risk of bank holding companies with large trading operations. The capital requirements are based on the banks' internal 99th percentile VaR forecasts with a 1-day horizon. Banks are required to maintain records of daily trading revenue for testing their VaR models. The daily trading revenue for 6 large trading banks is used in this study. ${ }^{3}$

All of the banks in the study meet the Basel MRA "large trader" criterion and are subject to market risk capital requirements. Four of the 6 banks are among the largest derivatives dealers world wide and the other two are among the largest in the U.S. The 6

\footnotetext{
${ }^{3}$ The 6 banks were studied in Berkowitz and O’Brien (2002) using a shorter sample period.
} 
trading banks and the sample periods for each bank were selected so as to exclude banks or periods for which there was a major merger which could substantially change the size and mix of trading. So as not to reveal dollar magnitudes, trading revenues are divided by the sample standard deviations of the respective banks' trading revenues.

Trading revenues are for the consolidated bank holding company and include gains and losses on trading positions, fee and spread income from customer transactions, and net interest income. Trading positions are required to be marked-to-market daily. Some smoothing of daily valuations is possible, although this would conflict with mark-to-market accounting rules. In this study, pricing inaccuracies are necessarily treated as a residual item. An attempt is made to represent the effects of fee and spread income and net interest income on trading revenues using proxy variables.

In Figure 1, kernel densities for the banks' trading revenues (divided by trading revenue standard deviations) are presented. A normal distribution having the same means and standard deviations as the banks' distributions is provided for reference. Descriptive statistics are presented in Table 1. As Figure 1 and Table 1 show, trading revenues are typically positive. For the median bank, mean daily trading revenues equal .78 trading revenue standard deviations. As shown in the bottom of Table 1, losses occurred on less than 20 percent of trading days for any bank. The typically positive trading revenues likely reflect the importance of fee and spread income and net interest income.

The trading revenue distributions also have high peaks and heavy tails, as revealed in Figure 1 and by the excess kurtosis statistics in Table 1 . The $5 \%$ and $95 \%$ quantiles for the banks' trading revenues in the bottom panel of Table 1 lie inside 5\% and 95\% quantiles that would be consistent with a normal distribution. The $1 \%$ and $99 \%$ and the $.05 \%$ and $99.5 \%$ 
quantiles lie outside quantiles consistent with a normal distribution. There also is no indication of any common skewness in the banks' trading revenue distributions

To provide more information on the heavy tails, the lowest and highest 10 percent returns for each bank are plotted by historical dates in Figure 2. The plotted values are expressed as deviations from trading revenue means and are divided by sample standard deviations. With some exceptions for bank 1, the lowest 10 percent returns are all losses. Several features of Figure 2 are notable.

One is that, while there is temporal clustering in both high and low returns, the clustering tends to be greater for low returns. This asymmetry in temporal clustering may be due to periodic large fees earned by dealers from customer transactions that are more evenly dispersed through time. In contrast, low returns are likely to reflect mostly portfolio losses from adverse market moves and persistency in market volatility (operational costs are not included in trading revenues).

A second and related feature of Figure 2 is that all of the banks encountered loss clustering, with some also experiencing positive spikes, during the market turmoil in the late summer and fall of 1998. The market instability during this period had important common effects on the banks' trading revenues. For all 6 banks, daily averages of trading revenues for the second half of 1998 were low and this period had a large effect on the full sample trading revenue kurtosis for banks' $1,2,3$, and especially $6 .{ }^{4}$

It should be noted that variation in dealer positions is also a potentially important determinant of the trading return distribution. The dependency of the trading return

\footnotetext{
${ }^{4}$ For the second half of 1998, daily averages of trading revenues for banks 1 to 6 were respectively .55, .39, $.22, .15, .15, .39$. If the second half of 1998 is excluded from the sample, the excess kurtosis for banks' 1 through 6 are respectively 4.30, 2.63, 2.84 4.42, 6.07, and 4.64. See Table 1 for comparable statistics for the full-period samples.
} 
distribution on the dynamic management of positions under a VaR-constraint is a major feature in Basak and Shapiro (2001).

Table 2 presents cross-bank correlations for daily trading revenues above the diagonal and, for comparison, cross-bank daily VaR correlations below the diagonal. The trading revenue correlations are all positive and significant using a standard t-test. The potential contribution of exposures to market factors on the trading revenue correlations is considered below. In contrast, the bank VaR correlations show no common pattern, as correlations are both positive and negative and vary widely.

\section{Factor Model with Varying Positions}

A factor model framework when positions are variable is developed here and used to guide the empirical specifications. Consider a portfolio with positions in $K$ risky securities and a risk-free asset. Positions in securities and the risk-free asset may be long or short and include those held indirectly through derivatives. For measuring the portfolio's sensitivity to market factors, bid-ask spreads are abstracted from and the values of short or long positions are measured at a single price, e.g., the mid-market price. The portfolio can be adjusted continuously but returns are observed only for discrete time units.

Let $t$ denote time measured in discrete units. At the start of $t$, the bank holds an amount $x_{k t}^{0}$ in risky security categories $k=1, \cdots, K$ and $x_{0 t}^{0}$ in the risk-free asset, which are referred to as the bank's positions. Positions may be carried over from $t-1$ or new positions may be set at the start of $t$ prior to any price changes since $t-1$. Positions and prices measured at the end of period $t$ are denoted by $x_{k}(t), x_{0}(t)$ and $p_{k}(t)$. The price of the risk-free asset is fixed at 1 . Using this notation, the values of the portfolio at the start of $t$ and at the end of $t$ are respectively 


$$
\begin{aligned}
W_{t}^{0} & \equiv \sum_{k=1}^{K} x_{k t}^{0} p_{k}(t-1)+x_{0 t}^{0} \\
W(t) & \equiv \sum_{k=1}^{K} x_{k}(t) p_{k}(t-1)\left(\frac{p_{k}(t)}{p_{k}(t-1)}\right)+x_{0}(t),
\end{aligned}
$$

For the factor model, we want to expresses the 1-period change in the portfolio value as a function of 1-period changes in market prices $r_{k}(t) \equiv\left(p_{k}(t)-p_{k}(t-1)\right) / p_{k}(t-1)$. If positions are fixed, the change in the portfolio value will be determined by the 1-period market price changes. However, if positions are variable, the change in the portfolio value can be affected by intra-period price movements not revealed in the 1-period price changes. Thus, the suitability of a factor model when portfolio values are observed only discretely requires restrictions on intra-period position and/or possibly price changes. A highly simplifying assumption made here is that intra-period changes in security positions and prices are uniform over the period. This assumption becomes accurate for very short periods and it may be a reasonable approximation for 1-day returns. It implies that the intra-period position and price changes can be measured from the full period changes.

A second assumption is made to avoid complications from outside cash infusions or withdrawals: There are no exogenous intra-period capital flows to the portfolio and intraperiod cash payments and accrued interest on positions are accumulated in a separate account. Under this assumption, changes in positions at any time $\tau$ within period $t, d x_{k t}(\tau)$, made at prices $p_{k t}(\tau)$, will satisfy a self-financing constraint: $\sum_{k=1}^{K} d x_{k t}(\tau) p_{k t}(\tau)+d x_{0 t}(\tau)=0$.

Using the self-financing constraint and (1), the change in the portfolio value over the period, $w(t) \equiv W(t)-W^{0}(t)$, is 


$$
w(t)=\sum_{k=1}^{K}\left(x_{k t}^{0} p_{k}(t-1)+\frac{1}{2} \Delta x_{k}(t) p_{k}(t-1)\right) r_{k}(t)
$$

where $\Delta x_{k}(t)$ is the change in the position over period $t$ (see Appendix). Note that $x_{k t}^{0} p_{k}(t-1)+\frac{1}{2} \Delta x_{k}(t) p_{k}(t-1)$ is the average position in the period valued at the price of $k$ at the end of $t-1$.

The change in the portfolio value can be expressed using a factor model form:

$$
w(t)=\sum_{k=1}^{K} V_{k}(t) r_{k}(t)
$$

where $V_{k}(t) \equiv\left(x_{k}^{0}(t)+1 / 2 \Delta x_{k}(t)\right) p_{k}(t-1) . \quad V_{k}(t)$ is the value of the portfolio position in factor $k$ and measure's the portfolio's exposure to factor shock $r_{k}(t)$. Unlike the standard factor model assumption, the factor exposures are not constant. With daily data, they would reflect time-varying daily average positions. Two specifications of (3) will be considered. For the first specification, $V_{k}(t)$ is assumed to be a random draw from a stationary process with mean $\bar{V}_{k}$. Further, the positions' values, $V_{k}(t)$, are assumed to be independent of market factor changes and mutually independent. Under these conditions, the portfolio return in (3) satisfies the random coefficient models developed in Hildreth and Houck (1968).

With $\bar{V}_{k}$ as the mean position value in factor $k$ and $v_{k}(t) \equiv V_{k}(t)-\bar{V}_{k}$ as the random change in the position value, the details of the factor model can be expressed by 


$$
\begin{aligned}
& w(t)=\sum_{k=1}^{K} r_{k}(t) \bar{V}_{k}+u(t) \\
& u(t) \equiv \sum_{k=1}^{K} r_{k}(t) v_{k}(t) \\
& E[w(t)]=\sum_{k=1}^{K} \mu_{k}(t) \bar{V}_{k} \\
& \sigma_{\mathrm{ww}}=\sum_{k=1}^{K} \sum_{l=1}^{K} \bar{V}_{k} \bar{V}_{l} \omega_{k l}+\sum_{k=1}^{K} \sigma_{v_{k} v_{k}} \omega_{k k}
\end{aligned}
$$

where $\mu_{k} \equiv E\left[r_{k}(t)\right]$ is the expected change in the market price represented by factor $k$, $\sigma_{v_{k} v_{k}}$ is the variance for factor position $k$; $\sigma_{\mathrm{ww}}$ is the unconditional variance of changes in the portfolio value the portfolio, and $\omega_{k l}$ is the covariance (variance) for individual factors $r_{k}(t)$ and $r_{l}(t)$. For the analysis below, it is assumed that $\mu_{k}=0$.

Equation (4a) expresses the change in the value of the portfolio as the sum of change in value conditioned on average positions and the change in value conditioned on the positions’ realized random components, the latter being defined in (4.b). (4.c) and (4d) are the portfolio's unconditional mean change and variance. The unconditional variance is the sum of the variances for $\sum_{k=1}^{K} r_{k}(t) \bar{V}_{k}$ and $u(t)$. The variance is the sum of the factor variances and covariances weighted by the mean positions plus the sum of the products of the factor variances and position variances. Thus, with variable positions, the volatility of positions interacts with the volatility of the factors in determining the dispersion of portfolio returns.

The factor model in (4) also provides for the correlation between the changes in banks' $i$ and $j$ portfolio values that come from market factor shocks. This correlation represents a measure of cross-bank commonality in market risks. Using subscripts for banks’ $i$ and $j$, we have (see Appendix) 


$$
\rho_{w_{i} w_{j}}=\rho_{\hat{w}_{i} \hat{w}_{j}} \sqrt{R S_{i}} \sqrt{R S_{j}}+\rho_{u_{i} u_{j}} \sqrt{1-R S_{i}} \sqrt{1-R S_{j}}
$$

where $w_{i}(t)=\hat{w}_{i}(t)+u_{i}(t), \hat{w}_{i}(t) \equiv r(t) \bar{V}_{i}$ and $u_{i}(t)$ is the residual for bank $i$ in (4.b).

Equation (5) describes two sources of commonality in banks' market risks. $\rho_{\hat{w}_{i} \hat{w}_{j}}$ is the correlation between changes in $i$ and $j$ 's portfolio values when factor exposures are conditioned on the mean positions. One source of commonality is similar mean positions, which would make $\rho_{\hat{w}_{i} \hat{w}_{j}}$ positive. $\rho_{u_{i} u_{j}}$ is the correlation associated with the variation in positions as reflected in $u_{i}(t)$ and $u_{j}(t)$. A second source is common variation in positions. $R S_{i}$ and $R S_{j}$ determine the relative importance of these two sources of correlated returns. $R S_{i}$ is the (population) R-square from a regression of $i$ 's portfolio value changes on market factors with factor coefficients set at their means $\left(R S_{i} \equiv \sigma_{\hat{w}_{i} \hat{w}_{i}} / \sigma_{w_{i} w_{i}}\right)$.

Using the random coefficient model and with observations on trading portfolio value changes and market factors, it is possible to estimate the bank dealers' average factor positions and their variances and some components of the cross-bank correlations.

The assumptions of course are restrictive and limit the generality of results. The assumption that position changes are mutually independent is one of notational convenience but potentially important for empirical tractability if there are many factors. Dropping this assumption would require recognizing all the covariances between position changes in (4.d). Assuming that market exposures are independent of factor changes is particularly limiting because portfolio management may be related to market price movements. As discussed earlier, such polices have been said to adversely affect market stability. Dropping 
the assumption of independence has important effects on the factor model formulation and, specifically, can make portfolio returns non-linear in the factor changes, $r_{k}(t)$.

An illustration of this is when the portfolio is managed such that returns resemble a call or put option on say security $k$. The option-like portfolio implies a position in the security and a cash position. Changes in the security price have both first-order and higherorder effects on the portfolio return. The higher-order effects imply changes in the security and cash positions that are related to the factor price change. For security $k, \Delta x_{k}(t)$ in (2) is positive and depends on the price change, $r_{k}(t)$. A second-degree polynomial provides a second-order approximation to the effect of the market factor on the portfolio value.

$$
w(t)=a_{k}^{0}(t) r_{k}(t)+b_{k}^{0}(t)\left(r_{k}(t)\right)^{2}
$$

The coefficient for the linear component in (6) is analogous to the option's delta and that for the quadratic component to the option's gamma.

Non-linear portfolio return equations such as (6) and returns expressed as functions of traded option values have been used in hedge fund studies to capture positions that vary with market returns. ${ }^{5}$ However, a particular portfolio strategy, including the strategy horizon, is needed to specify or interpret a particular functional form. For example, the strategy specified in the preceding illustration implies the squared market factor in (6) reflects the non-linear sensitivity of the portfolio to the market factor, i.e., the option’s "gamma." Without this specification, the interpretation of the squared factor would be ambiguous (e.g.,

\footnotetext{
${ }^{5}$ Chan et al (2004) use higher-order polynomials in market factors to capture non-linearity in hedge fund returns. Agarwal and Naik (2004) use returns to call and put options as the factors in hedge fund factor regressions to capture the non-linearity between the hedge fund's returns and the underlying market factors that arises from option-type trading strategies. Mitchel and Pulvino (2001) apply a piecewise linear factor model in returns to risk arbitrage strategies
} 
it might represent the sensitivity of the portfolio value to market volatility). Further, the coefficients $a_{k}^{0}(t)$ and $b_{k}^{0}(t)$ expressed in (6) are for period $t$. They depend on the security value at the start of the period and also the portfolio management horizon (option's time to expiration). Treating the two coefficients as constants implies that the portfolio is being rebalanced to a constant composition and horizon at the start of each sample observation, e.g., each month if observations are monthly.

For bank dealers, we have little specific information on their portfolio strategies and are not testing a specific strategy. This lack of specificity includes the time dimension of the dealer's strategy as it relates to our daily observation period.

A less formal approach to price-dependent strategies is taken here. For each bank, we estimate a linear regression of trading revenues on market factor changes (and non-market factor variables) with 150-day daily rolling samples. For the 6 banks, the estimated rolling coefficients are plotted along with coincidental 150-day rolling means for the respective factors (factor price levels, not changes). The 150-day rolling means will reflect periods of rising or declining market prices. Of interest is whether the rolling factor coefficients move systematically with the factors. This would indicate dealers' market exposures vary with the market factors and, hence, a possible price-dependent strategy. The significance of any comovement will be judged according to whether or not it is common among the 6 banks.

While observed comovement between the factor coefficients and the factors would indicate that the dealers' market exposures are related to the market factors, this may still not uniquely identify the price-dependent portfolio strategy. We consider this issue in evaluating the rolling regression results. 
Before presenting the empirical factor models, the treatment of other components of trading revenues needs to be mentioned: (1) Portfolio revenues include accrued and explicit interest payments and payments for risk-bearing. (2) Trading revenues also includes fee and spread income from market-making. We do not have direct measures of these additional components. Proxy variables are used to capture the effects of trading volume and net interest income on dealer trading revenues. (3) Portfolio revenues also are affected by (interperiod) changes in the portfolio's capital. Changes in the capital of the portfolio are not explicitly accounted for other than what can be represented by a trend variable.

\section{Random Coefficient Model}

We first describe the explanatory variables used in the empirical analysis.

\subsection{Explanatory Variables}

In selecting market factors, four broad market categories are represented: exchange rates, interest rates, equity, and credit spreads. For exchange rates, equities, and credit spreads multiple factors are used for each category. A 10-year U.S. Treasury rate is used to capture interest rate risk in the trading portfolio. In an earlier version, a 10-year rate and a 3month rate were used, with qualitatively similar coefficients estimated for both factors. There are a total of 11 market factors, which are identified in the top panel of Table 3 with descriptive statistics.

For exchange rate factors, regional exchange rate indices were constructed. They are weighted averages of log changes in individual country exchange rates. The exception is Russia, the only Eastern Europe country for which we had historical data. The weights are shown in the bottom panel of Table 3. They were constructed from world-wide dealer FX spot and derivatives turnover reported in BIS Central Bank Surveys in 1998 and 2001. 
Exchange rate and equity factors are measured as log differences; interest rate and credit spread factors are first differences. For the exchange rate and equity market factors, positive differences indicate increases in asset values and, for the interest rate and credit spreads, positive differences indicate decreases in asset values.

In addition to the market factors, a proxy variable is used to represent trading volume that generates fee and spread income. We have do not have direct information on dealers' daily transactions and use de-trended daily volume on the NYSE plus NASDAQ to represent a market volume influence on trading revenue. Also, we do not have data on net interest income from trading positions. To proxy for net interest income, we use a monthly lagged moving average of the 10-year U.S. Treasury rate. This is intended to represent the gradual realization in the portfolio of upward and downward movements in interest rate levels.

A trend variable is used to capture any trend in the level of the bank's activity. Lagged trading revenue is also included. If dealers smooth position revaluations, this could produce serially correlated returns.

\subsection{Market Risk Estimates}

We use the GLS random coefficient estimators developed by Hildreth and Houck (1968) to estimate the banks' mean exposures to the market factors, $\bar{V}_{k}$ shown in (4.a), and the exposure variances, $\sigma_{v_{k} v_{k}}$ shown in (4.d) and (4.e). ${ }^{6}$ For the estimation we are assuming that $v_{k}(t)$ is iid, independent of the market factors and that $v_{k}(t)$ and $v_{l}(t)$ are independent for $k \neq l$. The residual in the trading revenue equation will include the residual that arises from random position changes, i.e. $u(t)$ in (4.b), as well as any independent sources of

\footnotetext{
${ }^{6}$ Specifically, we use (14), p. 587, to estimate the coefficient variances and $\tilde{\beta}$ estimator in (25), p. 589, to estimate the mean market factor positions.
} 
trading revenue not accounted for in the model. Under these assumptions, Hildreth and Houck provide unbiased and consistent estimators of the mean coefficients and coefficient variances. Here, we allow only the 11 market factors to have variable coefficients.

Appendix Tables A.1 and A.2 contain the detailed regression results. Reported coefficients are estimated using trading revenues divided by sample standard deviations and thus measure trading revenue effects in terms of trading revenue standard deviations. The estimates are discussed here using several summary tables. In the top part of Table 4, summary statistics for the regressions estimating mean exposures to the market factors and including other regressors are presented. As shown, the full set of regressors has significant explanatory power based on F-values and regression R-squares. However, the F-values measuring the joint explanatory power for the 11 market factors are not very high and do not exceed the .05 critical value for 2 banks. Thus the market factors do not have a lot of explanatory power (excluding these factors from the regressions, causes the R-squares to drop by about 4 basis points). Since the factor coefficients reflect the estimated mean factor exposures, this implies that average market exposures cannot account for much of the variability of trading revenues.

In contrast, equity volume, used as a proxy for market transactions volume, is positive for all banks and highly significant for all but one bank (Appendix Table A.1). Trading revenues also have a significant positive trend. The estimated coefficients for the movingaverage interest rate (to proxy interest income) and lagged trading revenue have mixed signs and significance across the banks.

The bottom part of Table 4 presents summary statistics for the regressions estimating the variances of the market factor coefficients. While R-squares are low, the F-values are 
highly significant, implying significant variability in the market factor coefficients. The estimator used for the variances of the market factor coefficients is unbiased under the model assumptions. While Hildreth and Houck suggest constraining the coefficient estimates to non-negative values (pp. 587-589), this constraint was not imposed here. A little more than a third of the estimated coefficients are negative, although only 2 are significant at a .05 level and 1 at a .01 level (Appendix Table A.2). We regard the negative coefficients as reflecting sampling error and exclude them evaluating the variability of the dealers' market exposures. We have no reason to believe that this biases our interpretation of the results

In Table 5, two measures of the dealers' potential exposures to large market factor shocks are constructed using Appendix Tables A.1 and A.2. The top number in each cell is equal to the respective factor's coefficient from Table A.1—the estimate of the bank's mean exposure to the factor-multiplied by a two standard deviation shock to the factor. Recall that the coefficient estimates measure trading revenue effects in terms of trading revenue standard deviations. Hence, the top number in the cell measures trading revenue effects in terms of trading revenue standard deviations from a two standard deviation factor shock.

The two numbers underneath are the $2.5 \%$ and $97.5 \%$ estimated quantiles for factor exposures, i.e., 95 percent intervals. The quantile estimates use the estimated mean coefficients (Table A.1) and coefficient variances (Table A.2), and assume the coefficients are normally distributed. The quantile estimates also are multiplied by two standard deviation factor shocks. The shaded cells indicate where coefficient variance estimates are negative (a zero interval is reported but is not used the analysis below).

Consider first the estimated mean factor exposures (the top number in each cell). The estimates are small compared to the mean trading revenues shown in Table 1. For all 
factors, a 2 standard deviation market factor shock produces less than a .3 standard deviation change in a bank’s trading revenue and less than a .1 standard deviation change in trading revenue for two-thirds of the factors. For the median bank, mean trading revenues equal .78 standard deviations. Thus, 2 standard deviation shocks to individual factors and even to multiple factors would still leave a positive expected trading revenue.

Among individual market categories, the estimated mean exposures for the interest rate factor are negative for 5 of 6 banks. The negative exposures would imply bank dealers have (small) net long exposures to interest rate changes on average, i.e., the portfolio duration is positive. For the three other broad market categories, however, there does not appear to be a clear pattern of directional mean exposures to these market categories, although coefficients are mostly positive for the W. Europe exchange index. Generally, the coefficients vary in sign across broad market categories for a given bank and for the most part across banks for a given factor.

Now consider the estimated 95-percentile intervals for the market factor exposures reported under the mean exposure estimates in Table 5. The interval estimates cover both positive and negative values, indicating factor exposures can vary between long and short positions. Also, for the factor variances with non-negative estimates, the $95 \%$ coefficient bounds are large relative to the estimated mean coefficients. However, the bounds do not appear to be particularly large when measured against the trading revenue quantiles shown in the bottom panel of Table 1.

Specifically, the 95\% bounds in Table 5 measure potential trading revenue variation from 2 standard deviation market factor shocks. Conditioned on a 2-standard deviation factor shock, they represent $95 \%$ bounds on portfolio gains and losses. The trading revenue 
quantiles in Table 1 measure trading revenue variation due to market factor shocks and variation from other influences, such as market-making revenues. The bounds in Table 5 tend to be within the $1 \%$ and $99 \%$ quantiles for trading revenues shown in Table 1 . Also, the bounds in Table 5 are for 2 standard deviation market factor shocks. Thus, trading revenues conditioned on estimates of relatively large factor exposures and factor shocks do not produce extreme outliers relative to the unconditional variability of the trading revenues.

Overall, the results from the random coefficient model do not indicate that bank dealers take large market risks relative to the size of average trading revenues and trading revenue volatility and there is significant cross-dealer heterogeneity in exposures. However, at times dealers may still have large exposures to particular factors creating the potential for significant losses on days of extreme market conditions.

\subsection{Cross-Bank Trading Revenue Correlations}

As described earlier in section B, cross-bank trading revenues show small but consistently positive correlations (Table 2). As shown in equation (5) above, cross-bank trading return correlation due to market risk exposures can come from dealers either having common average exposures to market factors or common variation in exposures. Based on the random coefficient regression results, average factor exposures seem unlikely to be an important source of cross-bank trading revenue correlation. This can be determined by applying the mean and variance estimates of the random coefficients for the market factors to estimate $\rho_{\hat{w}_{i} \hat{w}_{j}} \sqrt{R S_{i}} \sqrt{R S_{j}}$ in (5) for banks' $i$ and $j{ }^{7}$ The cross-bank correlation component

\footnotetext{
${ }^{7} \rho_{\hat{w}_{i} \hat{w}_{j}}$ is generated by historically simulating $\hat{w}_{i}$ for each bank using the estimated factor coefficients and historical factor data. For $R S_{i}=\sigma_{\hat{w}_{i} \hat{w}_{i}} / \sigma_{w_{i} w_{i}}, \sigma_{\hat{w}_{i} \hat{w}_{i}}$ is similarly obtained. $\sigma_{w_{i} w_{i}}$ can be generated from
} 
reflecting positions at their mean values was calculated for each pair of banks. For all but one bank this component is less than .02 (for banks 2 and 4 , it is -.04 ).

If market exposures account for the most of the observed trading revenue correlations, it must be mainly due to common changes in banks' exposures, i.e., the

component $\rho_{u_{i} u_{j}} \sqrt{1-R S_{i}} \sqrt{1-R S_{j}}$ in (5). To determine this component, requires estimates of the variable exposure component $u_{i}(t)$ in each bank's residual revenue (equation (4b)). The best that can be done is to use the factor model regression residuals for $u_{i}(t)$ to calculate $\rho_{u_{i} u_{j}} \sqrt{1-R S_{i}} \sqrt{1-R S_{j}}$ for each combination of banks. Unfortunately, the regression residuals will include both $u_{i}(t)$ and other unspecified components of trading revenues.

Nonetheless, correlations reported in the bottom panel of Table 6 were obtained by calculating $\rho_{u_{i} u_{j}} \sqrt{1-R S_{i}} \sqrt{1-R S_{j}}$ using the regression equation residuals (correlations above the diagonal are the trading revenue correlations displayed in Table 2). The correlations below the diagonal typically are slightly more than half the trading revenue correlations above the diagonal. Whether the former represent a small commonality in trading revenue due to common market exposures or due to other common influences on trading revenues not controlled for in the regressions is difficult to say. Employing different approaches, further consideration is given to dealer commonality in market exposures in the next two sections

\section{Rolling Regressions}

In this section, we present estimates of market factor coefficients for daily rolling regressions. Using OLS, each bank's trading revenue is regressed on the market factors and

equation (4.e) in the text, using the estimated factor coefficients for $\bar{V}_{k}$, the sample factor variances for $\omega_{k k}$, and the estimated factor coefficient variances used for $\sigma_{v_{k} v_{k}}$. 
other explanatory variables, including our proxy variables for trading volume and net interest payment effects on trading revenues. The rolling window is 150 days. The first 150-day regression ends on August 11, 1998 (August 14, 1998 for bank 1). The regression equations are re-estimated daily dropping the last day and adding a new day using each bank’s available sample period.

In Figures 3a-3d, plots of rolling coefficients that are representative of the results for the different broad market categories are presented along with 150-day coincidental moving averages of the respective factors. The coefficients for each factor are in the same units as the random coefficient model estimates in Appendix Table A.1 (average values of the rolling coefficients are of the same order of magnitude as those in the random coefficient model in Table A.1). The rolling means of factors are expressed as factor levels (not differences). They show large ranges of variation over the sample period that includes a business cycle peak in March 2000 and a trough in November 2001. The interest rate, equity and credit spread factors (Baa and high yield) show evidence of business cycle influences.

Our interest is in whether the rolling coefficients vary systematically with the factors, which would indicate that the dealers' market exposures are related to market prices.

Consider first the coefficients for the interest rate factor plotted in Figure 3a. The coefficients for all but bank 4 show a rising and declining pattern that roughly tracks the rising and declining interest rate pattern. The pattern implies a tendency for the portfolio's interest rate exposure to move inversely with interest rates to the point where exposures may go from long to short or short to long.

This pattern would be consistent with dealers' reducing net long positions in longerterm securities when interest rates are rising even to the point of taking short positions. 
When interest rates decline, dealers increase their net long positions so that, in low interest rate environments, they tend to have relatively large interest rate exposures.

A more passive strategy also might be consistent with the results in Figure 3a. As shown in equation (3), the factor coefficients measure factor exposures in terms of position values. Rather than actively alter positions, dealers might have simply held their same positions and allowed position values to deteriorate, even becoming negative, as rates increased (prices declined) and then increase as rates subsequently declined. Against this explanation, however, market analysts suggested that dealers were increasing their long-term positions as interest rates declined to low levels in the early 2000s. ${ }^{8}$

Aside from the explanation for the rolling interest rate coefficients, it is shown in Table 7 that cross-bank correlations for the coefficients are all positive. This re-enforces the impression from Figure 3a of common variation in the dealers' interest rate exposures.

For the most part, the rolling coefficients for the other factors do not show any clear patterns of comovement with their respective factors that are common to all or most banks. In Figures 3b and 3c, plots are presented for the rolling coefficients and factors for the NYSE and high yield spreads. These results are representative of results for the other factors as well, excluding the Russian ruble (see below). For some individual banks, co-movement is observed between the coefficients and factors-e.g., the NYSE rolling coefficients and NYSE factor for bank 2. Whether this represents an underlying relationship for a particular bank or just a chance realization of the data can't be determined. Nonetheless, for the noninterest rate factors, the results do not indicate any covariation between the factor exposures and the factors that is common among the dealers.

\footnotetext{
${ }^{8}$ See Financial Times article by Jenny Wiggins, March 11, 2004. Also see Adrian and Fleming (2005), p. 4.
} 
Something of an exception to these results is the behavior of the Russian ruble coefficients shown in Figure 3d. For all 6 banks, the coefficients move toward zero in late August and early September 1998 as the ruble declined precipitously. The estimated coefficients remain close to zero until mid-1999 (several months after the August-October 1998 period passed out of the rolling samples). This behavior would be consistent the banks becoming insulated against the ruble. ${ }^{9}$

\section{Dealer Trading Revenues on Days of Large Market Moves}

The results from the two factor model approaches suggest that, in the aggregate, bank dealers are not consistently on one side of the market, except possibly for (default-free) interest rate exposures. However, as described in section 2, all 6 banks had abnormally low, though still mostly positive, trading revenues in the latter part of 1998. This was a period that included both high market volatility and sharp declines in credit and other risky asset prices and increases in U.S. Treasury security prices. In a final exercise, we look to see whether dealer trading revenues might be commonly related to price movements on days of large price changes. This may not be evident in the factor model regressions based on the full samples where on many days price changes are small.

For simplicity, days of relatively large price increases and, separately, price declines are identified only for the broad market categories—exchange rate, equity, interest rate and credit. For each market factor, days where factor shocks fall into the 1st quintile and the 5th quintile are separately sorted. For a market category, a large market decline day (a large market increase day) is defined as a day where at least one factor in the category is in the 1st

\footnotetext{
${ }^{9}$ While difficult to see in the Figure, prior to convergence to zero, the rolling coefficients across the 6 banks were quite different and included both positive and negative coefficient values, implying long and short exposures in the ruble. Note also that the volatility of the ruble (measured as absolute daily log changes) remained above pre-August 1998 levels over the rest of the year and into the first half of 1999.
} 
(the 5th) quintile and none is in the 5th (the 1st) quintile. For example, a day when the change in the NYSE index is in the 1st quintile and the NASDAQ index is not in the 5th quintile is a large equity market decline day. Typically, when one factor in a market category experiences a large change, other factor(s) in that category change in the same direction, although this is less true for exchange rates (further description of the large factor changes is provided in Table 8). Large market move days span the entire 6-year sample period but with a higher frequency in the second half of 1998.

Mean and median bank trading revenues, for low and high market return days for each of the four market categories are reported in Table 8. Except for the interest rate category, mean and median trading revenues for the 6 banks on low return days in each of the other market categories are not uniformly lower, or higher, than on high return days. For these market categories, this comparison does not indicate that dealers market exposures bear a common systematic relation to market prices. For the interest rate category, on days of large rate increases, trading revenues are uniformly lower across the 6 banks than on days of large rate declines, suggesting long (positive duration) interest rate exposures are typical. These results are consistent with the results from the factor models.

While heterogeneity in exposures will reduce the likelihood of large aggregate dealer losses, the chance realization of losses (or abnormally high returns) for a group of dealers is still more likely during a period when volatility is high across markets. The summer and autumn of 1998 was such a period and the higher volatility in the banks' trading revenues is apparent from Figure 2. ${ }^{10}$ Nonetheless, with cross-bank heterogeneity in exposures, losses

\footnotetext{
${ }^{10}$ We also looked at absolute trading revenues on days of high and low absolute changes in market factors, where absolute values are used to measure the size of daily fluctuations or volatility. Days of high and low volatility were defined at the market category level using an analogous procedure to that followed in determining days of large market declines and large increases (Table 8), except in terms of the size of absolute
} 
are likely to come from positions in different markets. For the 1998 third and fourth quarters, major U.S. bank dealers reported quarterly losses or low revenues in different market categories — interest rate (including credit), equity, and commodities. ${ }^{11}$ For the 6 banks' studied here, it was also the case that different banks reported quarterly losses or low returns in different markets.

\section{Conclusions}

To recap the main results, the bank dealers do not consistently maintain exposures on one side of the market, with the exception of small average long exposures to interest rate risk. They vary their exposures in size and direction but, except for interest rate exposures, the variation is heterogeneous across the dealers. Interest rate exposures tend to vary inversely with the level of interest rates. Variation in trading revenues from market exposures also does not seem large relative to the variation in total trading revenues that also include fee, spread and net interest income.

These results are subject to important limitations imposed by limitations of the trading revenue data that were used, inherent factor model limitations, and to a small sample of bank dealers. Also, the two factor modeling approaches employ different underlying assumptions whose consequences have not been examined. If these limitations are put aside, a number of points can be made about the relation between dealer market risks, VaR, and market prices based on the results.

factor changes. For each of the 6 banks, mean and median absolute 1-day trading revenues are consistently higher on high market volatility days than on low market volatility days for all 4 market categories, with significance at the .05 level for almost 75 percent of the mean and median calculations.

${ }^{11}$ For large bank dealers, see "Bank Derivatives Report, Fourth Quarter 2001,” Office of the Comptroller of the Currency, p. 13. Note that the quarterly revenue reports include fee and spread income, as well as changes in position market values. 
Heterogeneity in dealers' market exposures reduces the likelihood that dealers as a group will incur large losses in periods of market stress or that their aggregate risk taking behavior contributes significantly to a "herding" phenomenon. The heterogeneity in exposures also applies to arguments that dealers' common use of VaR for risk management leads to herding behavior. Shifts in market volatility could produce common changes in dealers' VaRs and desired risk exposures but without leading to common directional shifts in risky asset demands because dealers have both short and long positions. A potential exception is commonality in adjustments to interest rate risk exposures.

While heterogeneity in dealers' market exposures reduces the likelihood of large aggregate dealer losses, the chance occurrence of common losses (or abnormally high returns) among banks is still more likely in a period of generally high market volatility. The summer and autumn of 1998 was such a period when volatility was high across markets and dealers’ losses or low returns occurred in different markets.

Especially during periods of extreme market conditions, there are areas of dealer activity other than securities trading that may be more important to financial market stability and bank risk. This would include dealers' market-making role under extreme market conditions. For example, see Routledge and Zinn (2004) with some empirical evidence on the summer and autumn of 1998 in Furfine and Remolona (2002)). Also potentially important is dealer, including parent bank, credit exposures to hedge funds and other important market players. The issue of bank credit exposures to hedge funds and large market players is taken up in Kho, Lee, and Stulz (2000), Furfine and Remolona (2002), and Chan, Getmansky, Hass, and Lo (2005). 


\section{REFERENCES}

Adrian, T. and M. Fleming (2005), "What Financing Data Reveal about Dealer Leverage,” Current Issues in Economics and Finance, Federal Reserve Bank of New York, March.

Agarwal, V. and N. Naik (2004), "Risks and Portfolio Decisions Involving Hedge Funds," The Review of Financial Studies,” vol 17, no. 1, 63-98.

Alexander, G. and A. Baptista (2004), “A Comparison of VaR and CVaR Constraints on Portfolio Selection with the Mean-Variance Model,” Management Science, vol 50, no. 9, 2004, 1261-1273.

Basak, S. and A. Shapiro (2000), "Value-at-Risk Based Risk Management: Optimal Policies and Asset Prices,” Review of Financial Studies, 14, 371-405.

Berkowitz, J. and J. O’Brien (2002), “How Accurate are Value-at-Risk Models at Commercial Banks?” Journal of Finance, 57, 1093-1112.

Brown, S. J. and W. N. Goetzmann (2001), “Hedge Funds with Style,” NBER Working Paper No. 8173.

Chan, N., M. Getmansky, S. Hass, A. Lo, (2004), "Systematic Risk and Hedge Funds," The Risks of Financial Institutions, NBER Conference October 22-23.

Chen, N., R. Roll, and S. Ross (1986), “Economic Forces and the Stock Market: Testing the APT and Alternate Asset Pricing Theories,” Journal of Business, 53, 383-404.

Cuoco, D. and H. Liu (2003), “An Analysis of VaR-based Capital Requirements,” manuscript, University of Pennsylvania, July

Danielsson, J., H.S. Shin, and J-P. Zigrand (2002), “The Impact of risk Regulation on Price Dynamics,” manuscript, available at http://www.riskresearch.org

Flannery, M. and C. James (1984), “The Effect of Interest Rate Changes on the Common Stock Returns of Financial Institutions,” The Journal of Finance, 39, 1141-1153.

Fung, W. and D. A. Hsieh (1997), "Empirical Characteristics of Dynamic Trading Strategies: the case of Hedge Funds,” Review of Financial Studies, 10, 275-302.

Furfine, C. and E. Remolona, "Price discovery in a market under stress: the U.S. Treasury market in fall 1998,” manuscript, Bocconi Centennial Conference, June 2002

Jorion, P. (2004), “Bank Trading Risk and Systematic Risk,” The Risks of Financial Institutions, NBER Conference, October 22-23.

Hildreth, C. and J. Houck (1968), "Some Estimators for a Linear Model with Random Coefficients,” Journal of the American Statistical Association, 63, 584-595.

Ko, B., D. Lee, R.M. Stulz (2000), “U.S. Banks, Crises,, and bailouts: From Mexico to LTCM,” American Economic Review, May, 28-31.

Leippold, M, F. Trojani, and P. Vanini (2003), “Equilibrium Impact of Value-At-Risk Regulation,” manuscript, University of Zurich, July. 
Mitchel, M. and T. Pulvino (2001), "Characteristics of Risk and Return in Risk Arbitrage,” The Journal of Finance, Vol LVI, No. 6, 2135-2175.

Morris, S. and H. S. Shin (1999), "Risk Management with Independent Choice," Oxford Economic Policy, 15, 52-62.

Persaud, A. (2000), "Sending the Herd off the Cliff,” Erisk

Routledge, B. and S. Zin (2004), "Model Uncertainty and Liquidity,” manuscript, Carnegie Mellon University, June.

Sharpe, W. (1992), “Asset Allocation: Management Style and Performance Measurement,” Journal of Portfolio Management, Winter, 7-19. 


\section{APPENDIX}

\section{Factor Model Derivations}

\section{Factor Model Portfolio Value (equation (2))}

Here the 1-period change in the value of the portfolio shown in equation (2) is derived. Two assumptions are used. One is a self-financing constraint within the period, $\sum_{k=1}^{K} d x_{k t}(\tau) p_{k t}(\tau)+d x_{0 t}(\tau)=0$. The second is that price and position changes within the period are uniform: $d p_{k t}(\tau)=\Delta p_{k}(t) d \tau$ and $d x_{k t}(\tau)=\Delta x_{k}(t) d \tau$ for $t-1<\tau<t$. The starting position for security $k$ is $x_{k t}^{0}$. The derivation uses continuous price and position changes within the period. The change in the value of the portfolio is $w(t) \equiv W(t)-W_{t}^{0}$.

Using the above assumptions and notation:

$$
\begin{aligned}
w(t) & =\int_{t=1}^{t}\left(\sum_{k=1}^{K} x_{k}(\tau) d p_{k}(\tau)+p_{k}(\tau) d x_{k}(\tau)+d x_{0}(\tau)\right) d \tau \\
& =\sum_{k=1}^{K} \int_{t-1}^{t} x_{k}(\tau) d p_{k}(\tau) \quad \text { (using the self-financing constraint) } \\
& =\sum_{k=1}^{K} \int_{t-1}^{t}\left(x_{k t}^{0}+\int_{t-1}^{\tau} d x_{k}(\varsigma) d \varsigma\right) d p_{k}(\tau) d \tau \\
& =\sum_{k=1}^{K}\left(x_{k t}^{0}+\frac{1}{2} \Delta x(t)\right) \Delta p(t) \quad \text { (using uniform price and position changes) } \\
& =\sum_{k=1}^{K}\left(x_{k t}^{0} p_{k}(t-1)+\frac{1}{2} \Delta x(t) p_{k}(t-1)\right) r_{k}(t)
\end{aligned}
$$

where $r_{k}(t) \equiv \Delta p_{k}(t) / p_{k}(t-1)$.

\section{Cross-Bank Portfolio Value Correlation Due to Market Factors (equation (5))}

The correlation in portfolio value changes between bank $i$ and $j$ due to market factor shocks is derived under the assumptions used for the random coefficient model presented in (4). The following vector notation is used here: $r(t), V_{i}(t), \bar{V}_{i}$ and $v_{i}(t)$ are $K \times 1$ vectors of 
the market factors, factor coefficients, mean coefficients and random coefficient components, respectively. The factor shocks $r(t)$ are assumed to have a zero expected value.

Using (4.a) in the text, $w(t)=\sum_{k=1}^{K} r_{k}(t) \bar{V}_{k}+u(t)$ and (4b), $u(t) \equiv \sum_{k=1}^{K} r_{k}(t) v_{k}(t)$, the expected cross-product of returns for banks $i$ and $j$, conditioned on $r(t)$, is:

$$
E\left[w_{i}(t) w_{j}(t) \mid r(t)\right]=E_{v_{i}, v_{j}}\left[\left(\bar{V}_{i}^{\prime} r(t)+v_{i}^{\prime}(t) r(t)\right)\left(\bar{V}_{j}^{\prime} r(t)+v_{j}^{\prime}(t) r(t)\right) \mid r(t)\right]
$$

where $E_{v_{i} v_{j}}\left[g\left(v_{i}, v_{j}\right) \mid r(t)\right] \equiv \int_{v_{i 1}} \cdots \int_{v_{j K}} g\left(v_{i 1} \cdots, v_{j K}, r(t)\right) f\left(v_{i 1} \cdots, v_{j K} \mid r(t)\right) d v_{i 1} \cdots, d v_{j K}$. Using $E\left[v_{i}(t)\right]=0$ and independence between $v_{i}(t)$ and $r(t), E_{v_{j}}\left[\bar{V}_{i}^{\prime} r(t) r^{\prime}(t) v_{j}(t) \mid r(t)\right]=$ $E_{v_{i}}\left[v_{j}^{\prime}(t) r(t) r^{\prime}(t) \bar{V}_{j} \mid r(t)\right]=0$. Using this orthogonality, (A.2) becomes

$$
\begin{aligned}
E\left[w_{i}(t) w_{j}(t) \mid r(t)\right] & =\bar{V}_{i}^{\prime} r(t) r^{\prime}(t) \bar{V}_{j}+E_{v_{i}, v_{j}}\left[v_{i}^{\prime}(t) r(t) r^{\prime}(t) v_{j}(t) \mid r(t)\right] \\
& =\bar{V}_{i}^{\prime} r(t) r^{\prime}(t) \bar{V}_{j}+\sum_{k=1}^{K} \sum_{l=1}^{K} \sigma_{v_{i k} v_{j l}} r_{k}(t) r_{l}(t)
\end{aligned}
$$

Since the factor shocks are zero mean, the (unconditional) covariance between portfolio returns to $i$ and $j$ is $\sigma_{w_{i} w_{j}} \equiv E\left[w_{i} w_{j}\right]=E_{r}\left[E\left[w_{i}(t) w_{j}(t) \mid r(t)\right]\right]$. Applying $E_{r}\left[E\left[w_{i}(t) w_{j}(t) \mid r(t)\right]\right]$ to (A.3) yields

$$
\begin{aligned}
\sigma_{w_{i} w_{j}} & =E_{r}\left[\bar{V}_{i}^{\prime} r(t) r^{\prime}(t) \bar{V}_{j}\right]+E_{r}\left[\sum_{k=1}^{K} \sum_{l=1}^{K} \sigma_{v_{i k} v_{j l}} r_{k}(t) r_{l}(t)\right] \\
& =\bar{V}_{i}^{\prime} \Omega \bar{V}_{j}+\sum_{k=1}^{K} \sum_{l=1}^{K} \sigma_{v_{i k} v_{j l}} \omega_{k l}
\end{aligned}
$$

where $\Omega \equiv E\left[r(t) r^{\prime}(t)\right]$ is the covariance matrix for $r(t)$ and $\omega_{k l} \equiv E\left[r_{k}(t) r_{l}(t)\right]$ the covariance for $r_{k}(t)$ and $r_{l}(t) . \bar{V}_{i}^{\prime} \Omega \bar{V}_{j}$ is the covariance between changes in bank $i$ and bank $j$ 's portfolio values conditioned on market exposures set at their mean values. $\sum_{k=1}^{K} \sum_{l=1}^{K} \sigma_{v_{i k} v_{j l}} \omega_{k l}$ is the covariance between changes in $i$ and $j$ 's portfolio values due to the interaction between the 
random shifts in the coefficients and the market factors. Note the sign for $\sigma_{v_{i k} v_{j k}} \omega_{k k}$ is the same as that for $\sigma_{v_{i k} v_{j k}}$.

To obtain the correlation coefficient for $w_{i}(t)$ and $w_{j}(t)$, define $\sigma_{\hat{w}_{i} \hat{w}_{j}} \equiv \bar{V}_{i}^{\prime} \Omega \bar{V}_{j}$ and $\sigma_{u_{i} u_{j}} \equiv \sum_{k=1}^{K} \sum_{l=1}^{K} \sigma_{v_{k} v_{j l} v_{k l}} \omega_{k l}$. Define $\rho_{w_{i} w_{j}}$ as the correlation between $w_{i}(t)$ and $w_{j}(t)$. Using this notation, we can express the various correlations and covariances between between changes in $i$ and $j$ 's portfolio values as follows:

$$
\begin{array}{ll}
\text { (A.5.a) } & \rho_{w_{i} w_{j}} \equiv \sigma_{w_{i} w_{j}} / \sqrt{\sigma_{w_{i} w_{i}}} \sqrt{\sigma_{w_{j} w_{j}}} \\
\text { (A.5.b) } & \sigma_{\hat{w}_{i} \hat{w}_{j}} \equiv \rho_{\hat{w}_{i} \hat{w}_{j}} \sqrt{\sigma_{\hat{w}_{i} \hat{w}_{i}}} \sqrt{\sigma_{\hat{w}_{j} \hat{w}_{j}}} \\
\text { (A.5.c) } & \sigma_{u_{i} u_{j}} \equiv \rho_{u_{i} u_{j}} \sqrt{\sigma_{\hat{w}_{i} \hat{w}_{i}}} \sqrt{\sigma_{\hat{w}_{j} \hat{w}_{j}}}
\end{array}
$$

Also, from (A.4), we have $\sigma_{w_{i} w_{j}}=\sigma_{\hat{w}_{i} \hat{w}_{i}}+\sigma_{u_{i} u_{i}}$. Using this result with the definitions in (A.5), gives the unconditional correlation between changes in $i$ and $j$ 's portfolio values shown in equation (5) in the text:

$$
\begin{aligned}
\rho_{w_{i} w_{j}} & =\rho_{\hat{w}_{i} \hat{w}_{j}} \sqrt{\frac{\sigma_{\hat{w}_{i} \hat{w}_{i}}}{\sigma_{w_{i} w_{i}}} \sqrt{\frac{\sigma_{\hat{w}_{j} \hat{w}_{j}}}{\sigma_{w_{j} w_{j}}}}}+\rho_{u_{i} u_{j}} \sqrt{\frac{1-\sigma_{\hat{w}_{i} \hat{w}_{i}}}{\sigma_{w_{i} w_{i}}}} \sqrt{\frac{1-\sigma_{\hat{w}_{j} \hat{w}_{j}}}{\sigma_{w_{j} w_{j}}}} \\
& =\rho_{\hat{w}_{i} \hat{w}_{j}} \sqrt{R S_{i}} \sqrt{R S_{j}}+\rho_{u_{i} u_{j}} \sqrt{1-R S_{i}} \sqrt{1-R S_{j}}
\end{aligned}
$$


Table 1. Daily Trading Revenue Descriptive Statistics ${ }^{1}$

\begin{tabular}{|c|c|c|c|c|c|}
\hline & \multicolumn{4}{|c|}{ Obs } & \multicolumn{3}{c|}{ Mean } & \multicolumn{1}{c|}{ Kurtosis } & Skewness \\
\hline Bank & \multicolumn{2}{|c|}{ Dates } & \multicolumn{1}{c}{ Oxcess } & 10.75 & -0.60 \\
2 & $1 / 98-12 / 00$ & 762 & 1.05 & 10.82 & 0.16 \\
3 & $1 / 98-9 / 00$ & 711 & 0.79 & 4.82 & 1.49 \\
4 & $1 / 98-9 / 01$ & 1524 & 0.77 & 13.13 & 0.46 \\
5 & $1 / 98-12 / 03$ & 1544 & 0.90 & 4.17 & -0.62 \\
6 & $1 / 98-12 / 03$ & 1551 & 0.62 & 6.46 & -3.98 \\
\hline
\end{tabular}

\begin{tabular}{|c|c|c|c|c|c|c|c|}
\hline & & \multicolumn{7}{|c|}{ Quantiles } \\
\cline { 3 - 8 } Bank & Loss Rate $^{2}$ & 0.005 & 0.01 & 0.05 & 0.95 & 0.99 & 0.995 \\
\hline 1 & 0.074 & -2.29 & -1.83 & -0.22 & 2.72 & 3.77 & 4.15 \\
2 & 0.132 & -3.05 & -1.98 & -0.63 & 2.39 & 3.93 & 5.15 \\
3 & 0.146 & -2.99 & -2.18 & -0.60 & 2.24 & 3.11 & 3.89 \\
4 & 0.111 & -1.83 & -1.63 & -0.54 & 2.71 & 4.08 & 4.57 \\
5 & 0.188 & -3.41 & -2.45 & -0.84 & 2.15 & 3.40 & 4.15 \\
6 & 0.147 & -1.87 & -1.40 & -0.55 & 2.16 & 3.49 & 3.90 \\
\hline
\end{tabular}

1. Trading revenues in both panels are divided by bank's sample standard deviations.

2. Loss rate is the fraction of days when reported trading revenues were negative. 
Table 2. Cross-Bank Trading Revenue Correlations and VaR (trading revenue above the diagonal and $\mathrm{VaR}$ below the diagonal)

\begin{tabular}{|l|rrrrrr|}
\hline \multicolumn{2}{r}{ Bank 1 } & \multicolumn{1}{c}{ Bank 2 } & Bank 3 & Bank 4 & \multicolumn{1}{c|}{ Bank 5 } & \multicolumn{1}{c|}{ Bank 6 } \\
\hline Bank 1 & & 0.415 & 0.210 & 0.182 & 0.028 & 0.145 \\
Bank 2 & -0.027 & & 0.112 & 0.070 & 0.158 & 0.147 \\
Bank 3 & 0.099 & -0.151 & & 0.243 & 0.169 & 0.145 \\
Bank 4 & 0.060 & -0.812 & 0.130 & & 0.048 & 0.146 \\
Bank 5 & -0.119 & 0.684 & 0.097 & -0.503 & & 0.094 \\
Bank 6 & -0.314 & -0.300 & -0.271 & 0.627 & -0.330 & \\
\hline
\end{tabular}


Table 3. Market Factors

3a. Market Factors: Daily Changes $1998-2003^{1}$

\begin{tabular}{|cc|cc|cc|cc|}
\hline $\begin{array}{c}\text { Exchange } \\
\text { Rates }\end{array}$ & $\begin{array}{c}\text { mean } \\
(\text { std dev) }\end{array}$ & Equity & $\begin{array}{c}\text { mean } \\
(\text { std dev) }\end{array}$ & $\begin{array}{c}\text { Interest } \\
\text { Rates }\end{array}$ & $\begin{array}{c}\text { mean } \\
\text { (std dev) }\end{array}$ & $\begin{array}{c}\text { Credit } \\
\text { Spreads }\end{array}$ & $\begin{array}{c}\text { mean } \\
\text { (std dev) }\end{array}$ \\
\hline W Europe & 0.00009 & nyse & 0.00012 & 10 -yr treas & -0.00084 & 10 -yr Baa & 0.00050 \\
& $(0.00558)$ & & $(0.01156)$ & & $(0.06302)$ & & $(0.03497)$ \\
Russia & -0.00107 & nasdaq & 0.00015 & & & 5 -yr hi yield & 0.00049 \\
& $(0.02274)$ & & $(0.02222)$ & & & & $(0.09338)$ \\
Asian Paci & 0.00012 & & & & & 10 -yr swap & -0.00007 \\
& $(0.00603)$ & & & & & & $(0.03185)$ \\
S America & -0.00037 & & & & & emerg mkt & -0.00060 \\
& $(0.00611)$ & & & & & & \\
(embi+) & $(0.24070)$ \\
\hline
\end{tabular}

3b. Exchange Rates with U.S. Dollar: Construction of Regional Indices ${ }^{3}$

\begin{tabular}{|cc|cc|cc|cc|}
\hline \multicolumn{2}{|c|}{ W Europe $(1998)$} & \multicolumn{2}{|c|}{ W Europe } & $(1999-02)$ & \multicolumn{2}{c|}{ Asian Pacific } & \multicolumn{2}{c|}{ South America } \\
\hline country & weight & country & weight & country & weight & country & weight \\
\hline Germany & 0.54 & Euro & 0.633 & Japan & 0.727 & Mexico & 0.658 \\
UK & 0.198 & UK & 0.222 & Austral & 0.136 & Brazil & 0.342 \\
France & 0.092 & Switzer & 0.102 & HK & 0.075 & & \\
Switzer & 0.127 & Sweden & 0.043 & Sing & 0.035 & & \\
Sweden & 0.043 & & & Korea & 0.027 & & \\
\hline
\end{tabular}

1. Units for factor means and standard deviations: Exchange rates and equity means are daily log differences of levels; interest rates and credit spreads are daily first differences of levels expressed as percentage points.

2. Credit spreads are spreads from treasury rates with the same maturity. Embi+ is JP Morgan's Emerging Markets Bond Spread Index Plus.

3. Regional exchange rates are weighted log differences. Weights are based on world-wide dealer FX Spot and derivatives turnover volume reported for different currencies. Turnover volume is taken mostly from the 2002 BIS Central Bank Survey. The survey date is June April 2001. June 1998 turnover volume from the 1999 Central bank Survey is used to determine weights for Western Europe currencies for pre-Euro 1998 (country coverage in the 1998 survey is limited). 
Table 4. Summary Statistics for Factor Model and Coefficient Variances Regressions

\begin{tabular}{|r|c|c|c|c|c|c|}
\hline & Bank 1 & Bank 2 & Bank 3 & Bank 4 & Bank 5 & Bank 6 \\
\hline \multicolumn{7}{|c|}{ Factor Model Regressions } \\
\hline regression R & 0.18 & 0.15 & 0.22 & 0.32 & 0.15 & 0.07 \\
regression F-values & 10.09 & 7.64 & 27.44 & 45.36 & 17.93 & 5.33 \\
market factor F-values & 1.84 & 1.05 & 2.36 & 7.93 & 0.97 & 1.88 \\
sample size (n) & 728 & 681 & 1,484 & 1,485 & 1,483 & 1,109 \\
\hline Coefficient Variance Regressions \\
\hline regression R \\
2 & 0.06 & 0.18 & 0.08 & 0.03 & 0.04 & 0.02 \\
regression F-values & 3.82 & 13.73 & 11.07 & 4.16 & 5.59 & 1.98 \\
sample size (n) & 728 & 681 & 1,484 & 1,485 & 1,483 & 1,109 \\
\hline
\end{tabular}

1. .05 critical F-values: for regression $F(16, n-16)=1.65$; for market factors $F(11, n-16)=1.80$.

2. .05 critical F-values: $\mathrm{F}(12, \mathrm{n}-12)=1.76$. 
Table 5. Scaled Factor Coefficients with $2.5 \%$ and $97.5 \%$ Quantiles $^{1}$

\begin{tabular}{|c|c|c|c|c|c|c|}
\hline & & & $\begin{array}{c}\text { est coef } \\
\text { quantiles }\end{array}$ & & & \\
\hline Factors $^{2}$ & Bank 1 & Bank 2 & & \multirow{2}{*}{$\frac{\text { Bank } 4}{0.076}$} & \multirow{2}{*}{$\frac{\text { Bank } 5}{-0.082}$} & Bank 6 \\
\hline \multirow[t]{2}{*}{ fx w.eur } & 0.062 & 0.063 & 0.051 & & & 0.062 \\
\hline & $0.062 \quad 0.062$ & -0.066 & $\begin{array}{ll}-0.732 & 0.833\end{array}$ & 0.076 & $-0.813 \quad 0.648$ & 0.062 \\
\hline \multirow[t]{2}{*}{ fx russia } & 0.041 & 0.082 & 0.228 & -0.004 & 0.028 & -0.047 \\
\hline & $\begin{array}{ll}-0.087 & 0.169 \\
\end{array}$ & $-0.410 \quad 0.575$ & $-0.586 \quad 1.042$ & $-0.004 \quad-0.004$ & $-0.461 \quad 0.516$ & $\begin{array}{ll}-0.047 & -0.047 \\
\end{array}$ \\
\hline \multirow[t]{2}{*}{ fx asia pac } & -0.216 & -0.103 & -0.024 & 0.046 & 0.034 & 0.007 \\
\hline & $\begin{array}{ll}-1.413 & 0.982 \\
\end{array}$ & $-1.422 \quad 1.215$ & $-0.909 \quad 0.861$ & $0.046 \quad 0.046$ & $\begin{array}{ll}-1.261 & 1.329\end{array}$ & 0.007 \\
\hline \multirow[t]{2}{*}{ fx so amer } & -0.049 & -0.071 & -0.006 & 0.057 & -0.080 & 0.164 \\
\hline & $\begin{array}{ll}-0.049 & -0.049\end{array}$ & $-0.071 \quad-0.071$ & $-0.688 \quad 0.676$ & $-0.932 \quad 1.046$ & $-0.080-0.080$ & 0.164 \\
\hline \multirow[t]{2}{*}{ nyse } & -0.126 & -0.118 & 0.052 & 0.237 & -0.149 & -0.045 \\
\hline & $\begin{array}{ll}-1.295 & 1.043 \\
\end{array}$ & $\begin{array}{ll}-1.087 & 0.850 \\
\end{array}$ & 0.052 & $\begin{array}{ll}-0.414 & 0.887 \\
\end{array}$ & $\begin{array}{ll}-0.149 & -0.149 \\
\end{array}$ & -1.334 \\
\hline nasdaq & 0.082 & 0.108 & 0.007 & -0.072 & 0.044 & -0.063 \\
\hline & $-0.650 \quad 0.815$ & 0.108 & $\begin{array}{ll}-0.081 & 0.094 \\
\end{array}$ & $\begin{array}{ll}-1.083 & 0.939\end{array}$ & $0.044 \quad 0.044$ & $-0.063 \quad-0.063$ \\
\hline 10 -yr treas & -0.276 & 0.101 & -0.190 & -0.204 & -0.071 & -0.088 \\
\hline & $\begin{array}{ll}-1.356 & 0.803 \\
\end{array}$ & 0.101 & -1.970 & $-0.204 \quad-0.204$ & $-1.979 \quad 1.836$ & -1.063 \\
\hline Baa sprd & -0.041 & 0.165 & -0.083 & 0.022 & -0.021 & 0.162 \\
\hline & $-0.041 \quad-0.041$ & $\begin{array}{ll}-0.938 & 1.268 \\
\end{array}$ & $-0.083 \quad-0.083$ & $0.022 \quad 0.022$ & $-0.021-0.021$ & 0.162 \\
\hline hi yld sprd & -0.081 & 0.011 & -0.168 & -0.189 & -0.037 & -0.227 \\
\hline & $-0.081 \quad-0.081$ & $\begin{array}{ll}-1.406 \quad 1.428 \\
\end{array}$ & $\begin{array}{ll}-1.219 & 0.883 \\
\end{array}$ & $\begin{array}{ll}-1.085 & 0.708 \\
\end{array}$ & $-0.037 \quad-0.037$ & -0.910 \\
\hline 10 yr swap sprd & -0.017 & -0.015 & 0.075 & 0.012 & 0.025 & -0.037 \\
\hline & $\begin{array}{ll}-1.193 & 1.159\end{array}$ & $-0.266 \quad 0.236$ & $-0.554 \quad 0.705$ & $0.012 \quad 0.012$ & $0.025 \quad 0.025$ & $\begin{array}{ll}-0.037 & -0.037\end{array}$ \\
\hline embi+ sprd & 0.006 & 0.081 & -0.134 & -0.347 & -0.032 & 0.047 \\
\hline & $-1.954 \quad 1.966$ & $\begin{array}{ll}-1.879 & 2.041 \\
\end{array}$ & $-2.094 \quad 1.826$ & -2.307 & $-1.992 \quad 1.928$ & -1.913 \\
\hline
\end{tabular}

1. Scaled coefficients equal the change in trading revenue measured in terms of trading revenue standard deviations due to 2 standard deviation factor shocks. Shaded cells indicate the estimated variance was negative.

2. Factors expressed as log changes for exchange rates and equity and first differences for interest rate and credit spreads. 
6. Cross-Bank Trading Revenue Correlation due to Market Factors ${ }^{1}$ (unconditional trading revenue correlations above diagonal; correlations due to market factors below diagonal)

\begin{tabular}{|l|rccccc|}
\hline & Bank 1 & Bank 2 & Bank 3 & Bank 4 & Bank 5 & Bank 6 \\
\hline Bank 1 & & 0.415 & 0.21 & 0.182 & 0.028 & 0.145 \\
Bank 2 & 0.301 & & 0.112 & 0.070 & 0.158 & 0.147 \\
Bank 3 & 0.139 & 0.064 & & 0.243 & 0.169 & 0.145 \\
Bank 4 & -0.011 & -0.028 & 0.138 & & 0.048 & 0.146 \\
Bank 5 & 0.029 & 0.121 & 0.042 & 0.017 & & 0.094 \\
Bank 6 & 0.123 & 0.107 & 0.056 & 0.063 & 0.045 & \\
\hline
\end{tabular}

1. The cross-bank correlations due to market factors were calculated using equation (5). For details of the calculations, see the explanation in the text. 
Table 7. Cross-Bank Correlations for Rolling Regression Coefficients ${ }^{1}$

\begin{tabular}{|r|ccccccccccc|}
\hline & xwe & xru & xap & xsa & nyse & nasdaq & r10yr & Baa & hy yld & swap & embi \\
\hline median correlation & 0.09 & 0.03 & 0.18 & 0.28 & 0.18 & 0.20 & 0.74 & 0.16 & 0.59 & 0.25 & 0.13 \\
percent pos correlation & 53 & 53 & 53 & 67 & 73 & 60 & 100 & 60 & 80 & 67 & 67 \\
\hline
\end{tabular}

1. There are 15 cross-bank correlations for each market factor. 
Table 8. Bank Trading Revenues Conditioned on Large One-Day Market Moves

\begin{tabular}{|c|c|c|c|c|c|c|c|c|c|}
\hline & \multicolumn{4}{|c|}{ Exchange Rate Change } & \multicolumn{5}{|c|}{ Interest Rate Change } \\
\hline & Decline & Increase & Decline & Increase & & Decline & Increase & Decline & Increase \\
\hline Bank & \multicolumn{2}{|c|}{ Trading Rev: Mean } & \multicolumn{2}{|c|}{ Trading Rev: Median } & Bank & \multicolumn{2}{|c|}{ Trading Rev: Mean } & \multicolumn{2}{|c|}{ Trading Rev: Median } \\
\hline 1 & 1.14 & 1.04 & 1.07 & 0.97 & 1 & $1.29 *$ & 1.00 & $1.22^{*}$ & 0.90 \\
\hline 2 & 0.87 & 0.85 & 0.82 & 0.78 & 2 & 0.93 & 0.85 & 0.82 & 0.80 \\
\hline 3 & 0.70 & 0.81 & 0.70 & 0.75 & 3 & $0.86^{*}$ & 0.71 & $0.90 *$ & 0.72 \\
\hline 4 & 0.85 & $0.98^{*}$ & 0.81 & 0.81 & 4 & 0.95 & 0.93 & 0.87 & 0.78 \\
\hline 5 & 0.60 & 0.61 & 0.55 & 0.59 & 5 & $0.69 *$ & 0.57 & $0.70^{*}$ & 0.55 \\
\hline 6 & 0.63 & 0.69 & 0.63 & 0.68 & 6 & $0.87 *$ & 0.63 & $0.81 *$ & 0.64 \\
\hline & \multicolumn{4}{|c|}{ Equity Price Change } & & \multicolumn{4}{|c|}{ Credit Spread Changes } \\
\hline & Decline & Increase & Decline & Increase & & Decline & Increase & Decline & Increase \\
\hline Bank & \multicolumn{2}{|c|}{ Trading Rev: Mean } & \multicolumn{2}{|c|}{ Trading Rev: Median } & Bank & \multicolumn{2}{|c|}{ Trading Rev: Mean } & \multicolumn{2}{|c|}{ Trading Rev: Median } \\
\hline 1 & 1.17 & 1.06 & 1.06 & 0.89 & 1 & 1.00 & 1.13 & 0.93 & 1.13 \\
\hline 2 & 0.93 & 0.77 & 0.86 & 0.78 & 2 & $0.72 *$ & 0.92 & $0.64 *$ & 0.84 \\
\hline 3 & 0.74 & 0.86 & 0.78 & 0.85 & 3 & 0.84 & 0.73 & 0.76 & 0.78 \\
\hline 4 & 0.83 & $1.20 *$ & 0.80 & $0.93^{*}$ & 4 & 1.01 & 0.91 & 0.85 & 0.83 \\
\hline 5 & 0.60 & 0.51 & 0.59 & 0.45 & 5 & 0.68 & 0.63 & 0.64 & 0.61 \\
\hline 6 & 0.82 & 0.72 & 0.75 & 0.75 & 6 & 0.73 & 0.73 & 0.66 & 0.77 \\
\hline
\end{tabular}

1. Bank trading revenue is normalized by full sample bank trading revenue standard deviations. Sample sizes for each of the "Decline" and "Increase" categories range from 167 to 606, depending on the bank. and the category. Sample sizes for each of the "Decline" and "Increase" categories range from 167 to 606, with a median of 323. For each factor in its designated market category (e.g., nyse for equity category), its mean value for the "Decline" quintile is 1 to 2 standard deviations below its mean value for the "Increase."

*Significant at .05 for difference between "Decline" and "Increase" day trading revenue mean (median) value. Means test is a standard difference of two means. Medians test uses the Mann-Whitney-Wilcoxon rank sum test for large samples. 


\section{Appendix Tables}

Table A.1. Market Factor Model for Bank Trading Revenue ${ }^{1}$

\begin{tabular}{|c|c|c|c|c|c|c|c|}
\hline & & & & $\mathrm{Ba}$ & & & \\
\hline Variable & & 1 & 2 & 3 & 4 & 5 & 6 \\
\hline constant & $\beta_{0}$ & -0.105 & 1.152 & -0.575 & -2.632 & 1.397 & 0.422 \\
\hline & $\mathrm{t}$-value & -0.26 & 2.81 & -2.54 & -11.24 & 5.51 & 1.44 \\
\hline fx we & $\beta_{1}$ & 5.568 & 5.652 & 4.528 & 6.771 & -7.380 & 5.575 \\
\hline & t-value & 0.92 & 0.94 & 1.02 & 1.64 & -1.52 & 1.13 \\
\hline fx russia & $\beta_{2}$ & 0.901 & 1.814 & 5.011 & -0.088 & 0.605 & -1.038 \\
\hline & t-value & 0.56 & 0.97 & 2.57 & -0.08 & 0.35 & -0.72 \\
\hline $\mathrm{fx}$ asia pac & $\beta_{3}$ & -17.873 & -8.553 & -2.006 & 3.794 & 2.843 & 0.550 \\
\hline & t-value & -3.02 & -1.45 & -0.47 & 1.01 & 0.58 & 0.13 \\
\hline fx s amer & $\beta_{4}$ & -3.993 & -5.830 & -0.506 & 4.637 & -6.527 & 13.453 \\
\hline & t-value & -0.60 & -0.91 & -0.12 & 1.03 & -1.43 & 2.43 \\
\hline nyse & $\beta_{5}$ & -5.437 & -5.112 & 2.241 & 10.230 & -6.432 & -1.959 \\
\hline & t-value & -1.19 & -1.14 & 0.79 & 3.50 & -2.06 & -0.53 \\
\hline nasdaq & $\beta_{6}$ & 1.855 & 2.440 & 0.148 & -1.621 & 0.985 & -1.410 \\
\hline & t-value & 0.92 & 1.19 & 0.10 & -1.07 & 0.62 & -0.89 \\
\hline $10-y r$ treas & $\beta_{7}$ & -2.192 & 0.804 & -1.507 & -1.618 & -0.566 & -0.696 \\
\hline & t-value & -2.23 & 0.78 & -2.38 & -2.89 & -0.85 & -0.99 \\
\hline Baa sprd & $\beta_{8}$ & -0.593 & 2.355 & -1.184 & 0.314 & -0.305 & 2.312 \\
\hline & t-value & -0.41 & 1.58 & -1.30 & 0.36 & -0.31 & 2.12 \\
\hline hi yld sprd & $\beta_{9}$ & -0.434 & 0.059 & -0.901 & -1.011 & -0.200 & -1.218 \\
\hline & t-value & -0.62 & 0.07 & -2.06 & -2.46 & -0.48 & -2.48 \\
\hline swap sprd & $\beta_{10}$ & -0.268 & -0.235 & 1.181 & 0.191 & 0.397 & -0.582 \\
\hline & $\mathrm{t}$-value & -0.21 & -0.21 & 1.53 & 0.28 & 0.51 & -0.64 \\
\hline embi+ sprd & $\beta_{11}$ & 0.013 & 0.168 & -0.279 & -0.722 & -0.066 & 0.097 \\
\hline & $\mathrm{t}$-value & 0.07 & 0.86 & -2.12 & -5.55 & -0.44 & 0.52 \\
\hline equity vol & $\beta_{12}$ & 0.353 & 0.418 & 0.223 & 0.363 & 0.083 & 0.236 \\
\hline & t-value & 3.78 & 4.21 & 4.97 & 8.07 & 1.71 & 4.00 \\
\hline 10 -yr treas & $\beta_{13}$ & 0.143 & -0.124 & 0.150 & 0.529 & -0.206 & 0.024 \\
\hline move ave & t-value & 1.91 & -1.60 & 4.07 & 13.42 & -5.03 & 0.47 \\
\hline $\mathrm{PL}_{\mathrm{t}-1}$ & $\beta_{14}$ & 0.142 & 0.181 & 0.203 & 0.227 & -0.081 & -0.028 \\
\hline & t-value & 4.03 & 5.09 & 8.30 & 9.65 & -3.17 & -1.07 \\
\hline trend & $\beta_{15}$ & 0.001 & 0.001 & 0.001 & 0.001 & 0.001 & 0.000 \\
\hline & t-value & 3.59 & 3.45 & 9.05 & 12.08 & 6.71 & 4.37 \\
\hline F-Stat2 & & 9.236 & 6.081 & 22.368 & 44.293 & 14.593 & 4.576 \\
\hline $\mathrm{R}^{2}$ & & 0.172 & 0.128 & 0.196 & 0.325 & 0.137 & 0.063 \\
\hline $\mathrm{N}$ & & 728 & 681 & 1484 & 1485 & 1483 & 1109 \\
\hline
\end{tabular}

1. 'Trading revenues are divided by the banks' sample standard deviations. Equity volume has been scaled by 1 million. Coefficients are estimated for equation (4.a) in the text with additional explanatory variables described in the text. A GLS estimator is used, which is described in Hilreth and Houck (1968). See their description for $\beta$, second equation in (25), p. 589. 
Table A.2. Estimates of Coefficient Variances for Market Factors ${ }^{1}$

\begin{tabular}{|c|c|c|c|c|c|c|c|}
\hline & & \multicolumn{6}{|c|}{ Bank } \\
\hline Variable & & 1 & 2 & 3 & 4 & 5 & 6 \\
\hline \multirow[t]{2}{*}{ constant } & $\overline{\alpha_{0}}$ & 0.48 & 0.40 & 0.44 & 0.57 & 0.56 & 0.90 \\
\hline & $\mathrm{t}$-value & 3.25 & 3.89 & 5.86 & 8.21 & 5.76 & 2.41 \\
\hline \multirow[t]{2}{*}{ fx w eur } & $\overline{\alpha_{1}}$ & -528.20 & 34.75 & 1281.02 & -87.84 & 1114.55 & -2052.03 \\
\hline & $\mathrm{t}$-value & -0.26 & 0.02 & 1.19 & -0.09 & 0.80 & -0.39 \\
\hline \multirow[t]{2}{*}{ fx russia } & $\alpha_{2}$ & 2.05 & 30.54 & 83.44 & -19.82 & 30.01 & -108.13 \\
\hline & $\mathrm{t}$-value & 0.10 & 2.18 & 5.85 & -1.51 & 1.62 & -1.75 \\
\hline \multirow[t]{2}{*}{ fx asia pac } & $\alpha_{3}$ & 2567.56 & 3111.68 & 1401.34 & -240.30 & 3002.21 & -449.13 \\
\hline & $\mathrm{t}$-value & 3.00 & 5.26 & 2.43 & -0.45 & 4.00 & -0.18 \\
\hline \multirow[t]{2}{*}{ fx s amer } & $\alpha_{4}$ & -1526.15 & -333.83 & 810.87 & 1705.42 & -862.05 & -2801.47 \\
\hline & $\mathrm{t}$-value & -1.71 & -0.54 & 1.57 & 3.58 & -1.28 & -1.13 \\
\hline \multirow[t]{2}{*}{ nyse } & $\alpha_{5}$ & 665.46 & 456.79 & -301.12 & 206.31 & -35.02 & 808.70 \\
\hline & $\mathrm{t}$-value & 1.28 & 1.19 & -1.22 & 0.90 & -0.11 & 0.56 \\
\hline \multirow[t]{2}{*}{ nasdaq } & $\alpha_{6}$ & 70.81 & -80.79 & 1.01 & 134.72 & -38.89 & -154.61 \\
\hline & $\mathrm{t}$-value & 0.56 & -0.70 & 0.02 & 2.23 & -0.46 & -0.51 \\
\hline \multirow[t]{2}{*}{10 -yr treas } & $\alpha_{7}$ & 19.11 & -4.55 & 51.94 & -8.02 & 59.64 & 15.60 \\
\hline & $\mathrm{t}$-value & 0.74 & -0.25 & 5.87 & -0.98 & 5.10 & 0.31 \\
\hline \multirow[t]{2}{*}{ Baa sprd } & $\alpha_{8}$ & -58.85 & 64.78 & |-78.46 & -29.95 & -16.59 & $\begin{array}{l}-69.86 \\
\end{array}$ \\
\hline & $\mathrm{t}$-value & -0.86 & 1.44 & -3.07 & -1.27 & -0.50 & -0.55 \\
\hline \multirow[t]{2}{*}{ hi yld sprd } & $\alpha_{9}$ & -0.15 & 15.00 & 8.25 & 6.00 & -0.55 & 3.48 \\
\hline & $\mathrm{t}$-value & -0.02 & 1.52 & 3.24 & 2.56 & -0.17 & 0.28 \\
\hline \multirow[t]{2}{*}{ swap sprd } & $\alpha_{10}$ & 88.76 & 4.04 & 25.43 & -15.60 & -15.92 & -24.42 \\
\hline & $\mathrm{t}$-value & 2.49 & 0.16 & 1.42 & -0.95 & -0.68 & -0.25 \\
\hline \multirow[t]{2}{*}{ embi+ sprd } & $\alpha_{11}$ & 1.39 & 1.68 & 0.19 & 0.37 & 0.56 & 4.73 \\
\hline & t-value & 3.11 & 5.73 & 0.78 & 1.68 & 1.79 & 4.44 \\
\hline F-Stat & F-Stat & 3.82 & 13.73 & 11.07 & 4.16 & 5.59 & 1.98 \\
\hline $\mathrm{R}^{2}$ & $\mathrm{R}^{2}$ & 0.06 & 0.18 & 0.08 & 0.03 & 0.04 & 0.02 \\
\hline $\mathrm{N}$ & $\mathrm{N}$ & 728 & 681 & 1484 & 1485 & 1483 & 1109 \\
\hline
\end{tabular}

1. The coefficients (variances) and their standard errors use an unbiased least-squares estimator developed in Hildreth and Houck (1968), equation (14), p.587. 
Figure 1. Densities for Bank Trading Revenues
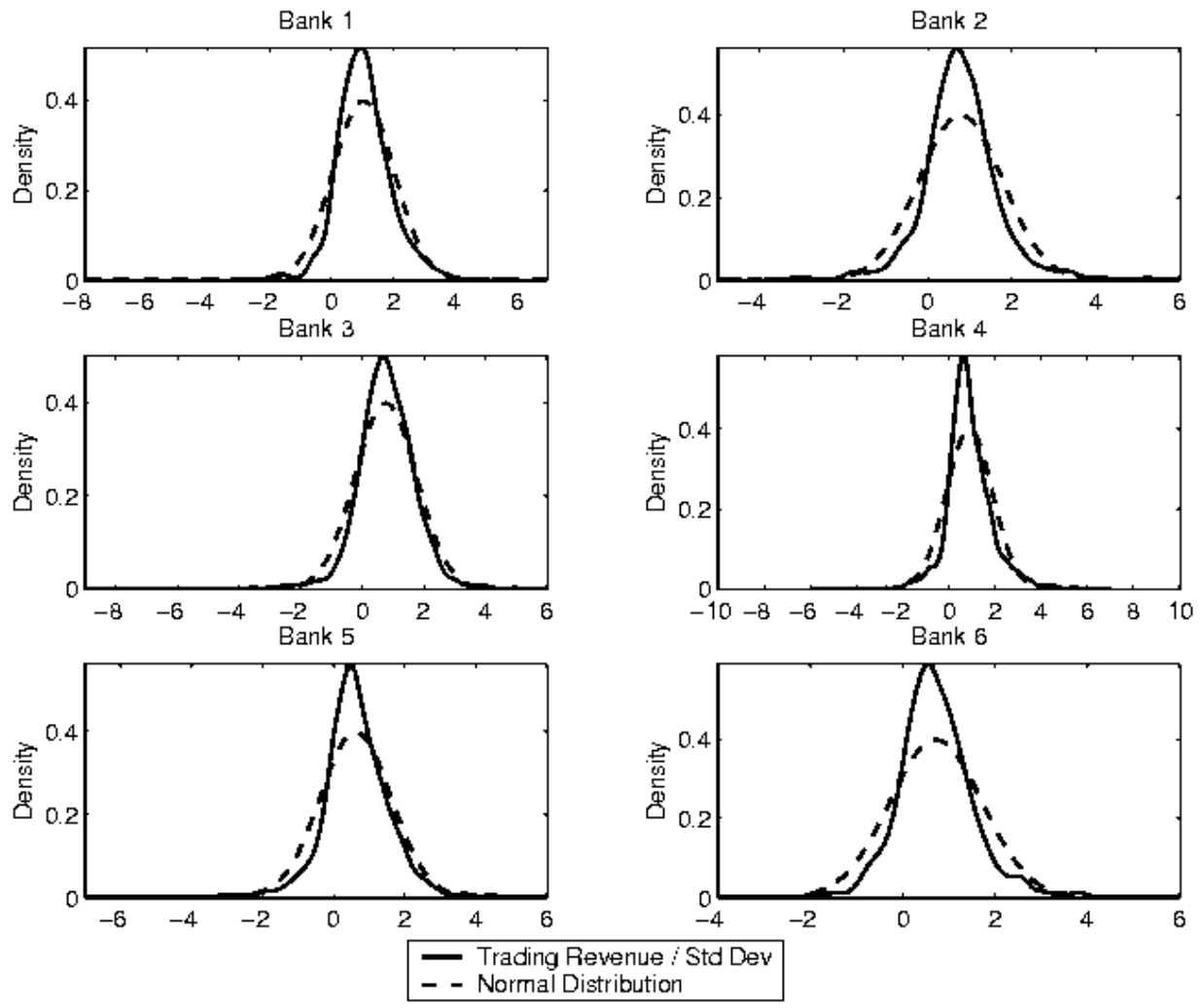
Figure 2. Trading Revenues: 10 Percent Lowest and Highest Values ${ }^{1}$
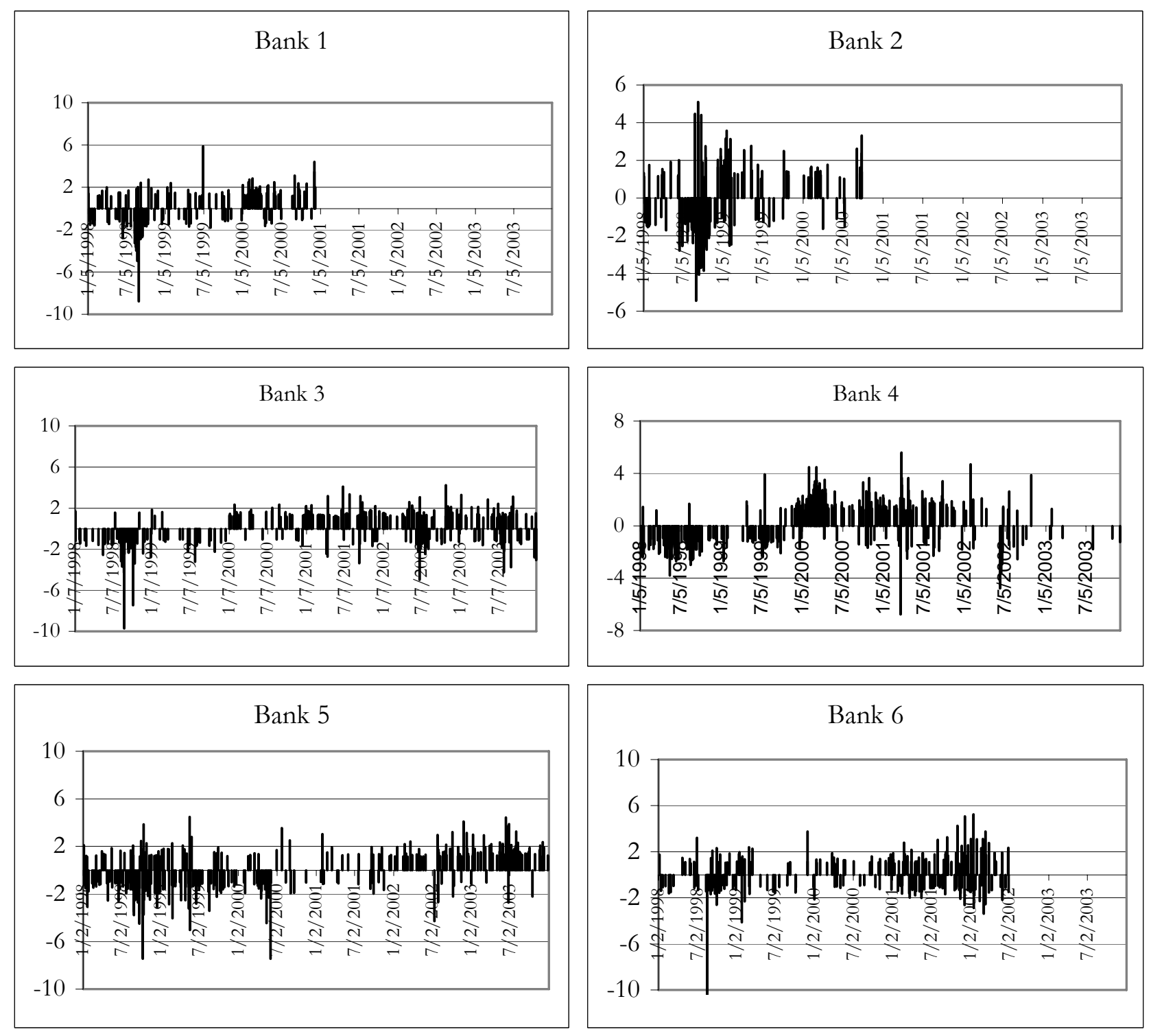

1. Values are expressed as deviations from the banks' sample means and in terms of the sample standard deviations. The large negative spike for Bank 6 exceeds 10 standard deviations 
Figure 3a. Interest Rate Regression Coefficients and Moving-Average Interest Rate
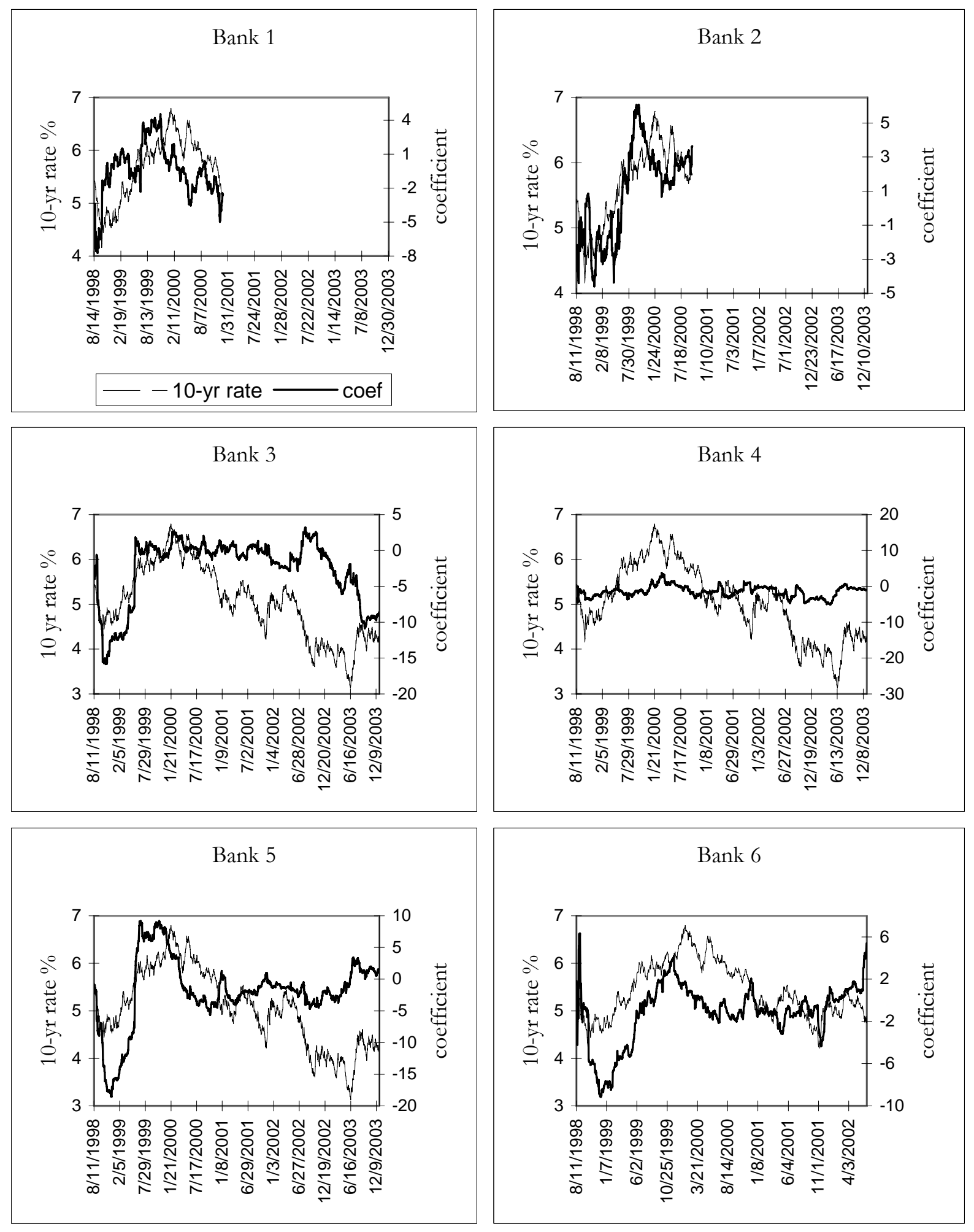
Figure 3b. NYSE Regression Coefficients and Moving-Average NYSE Index
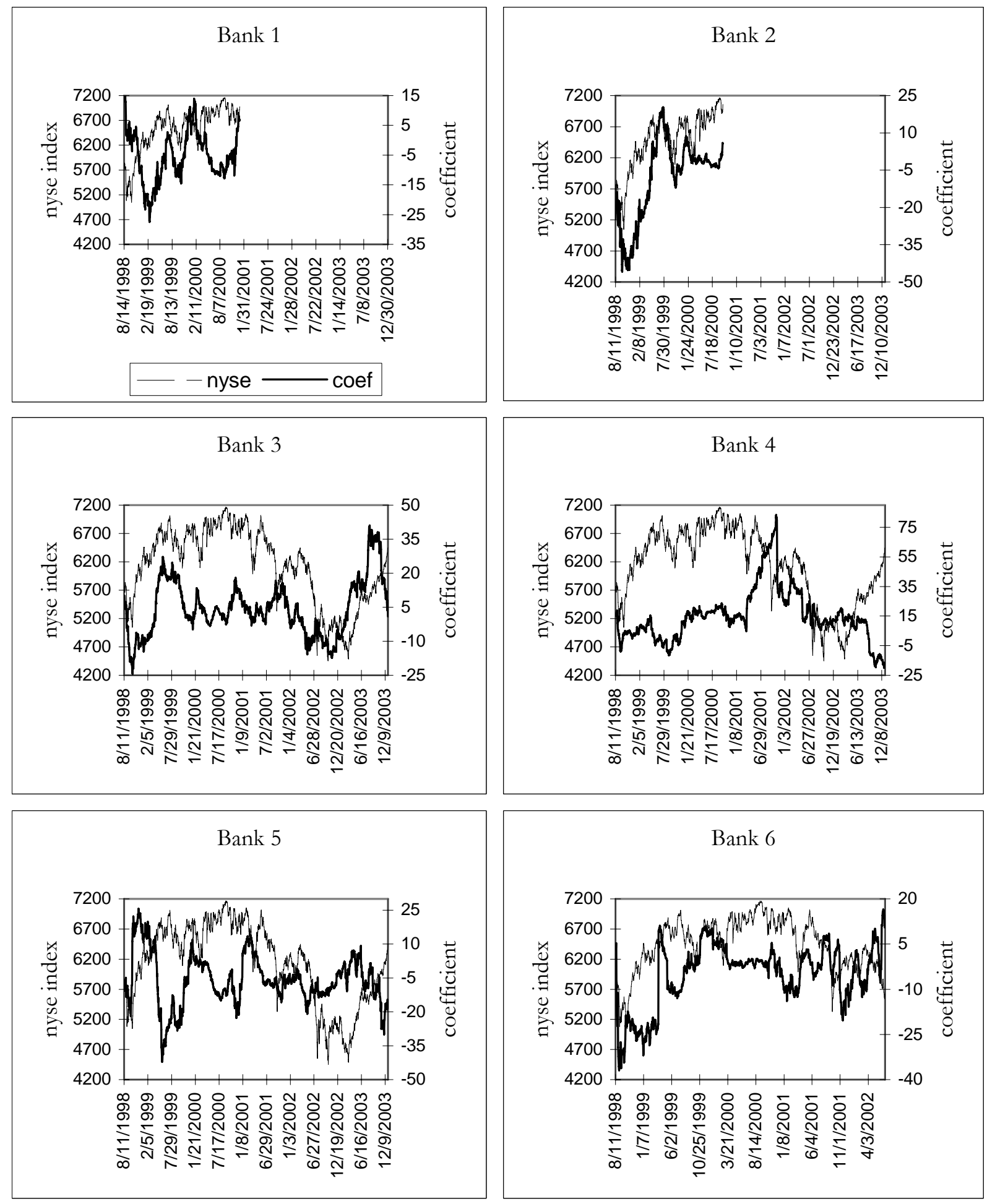
Figure 3c. High Yield Regression Coefficients and Moving-Average High Yield Spread
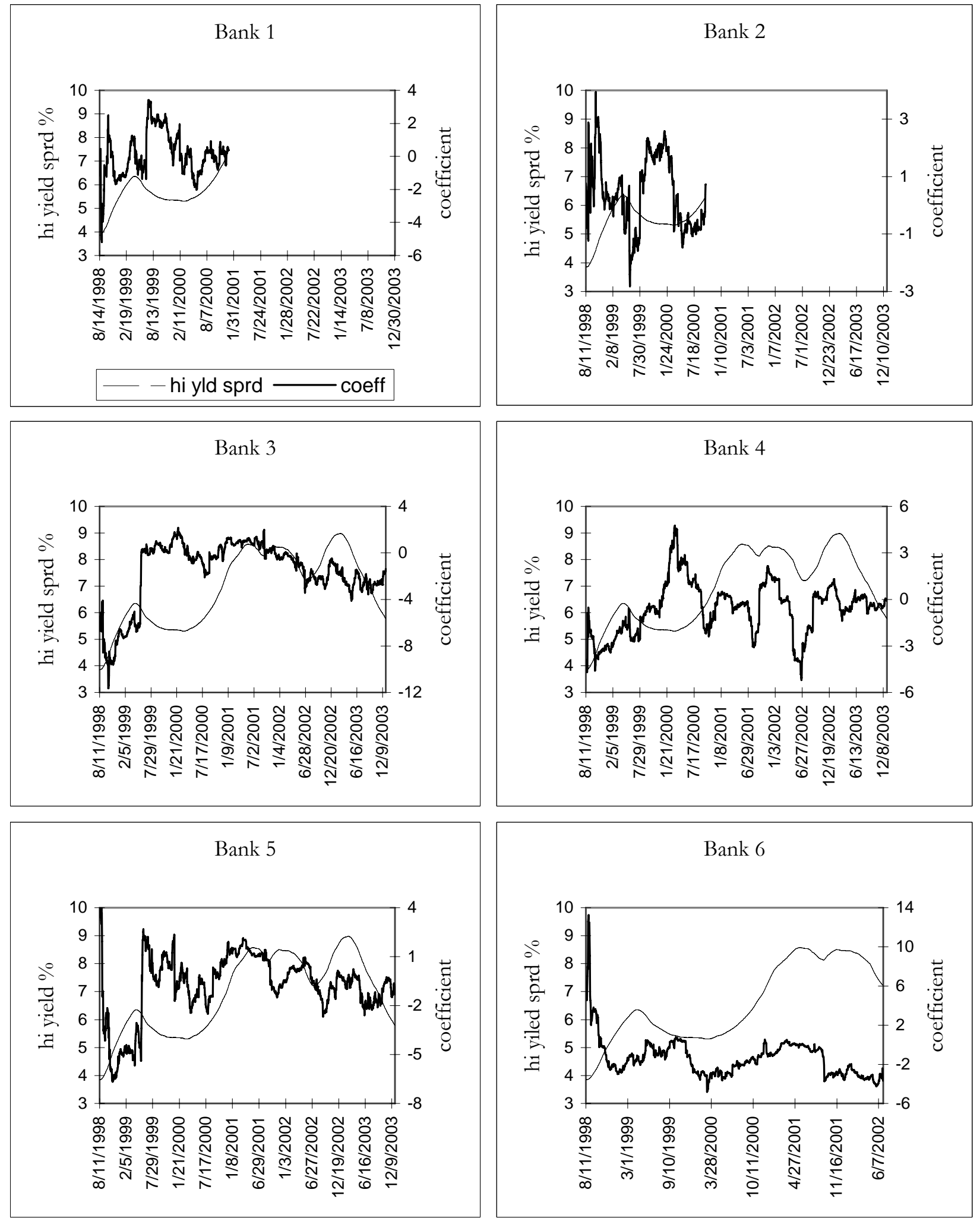
Figure 3d. Russian Ruble Regression Coefficients and Moving-Average Exchange Rate
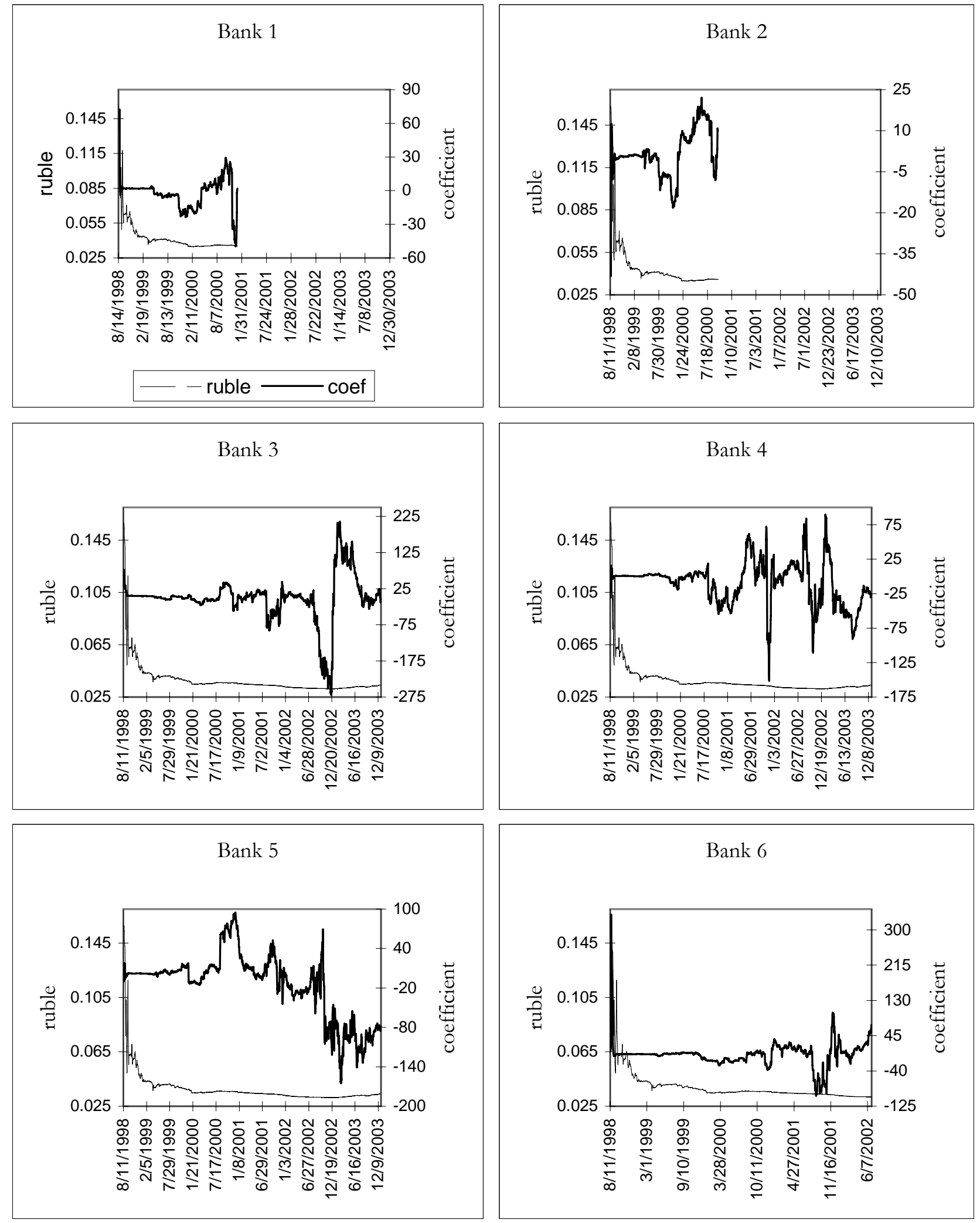